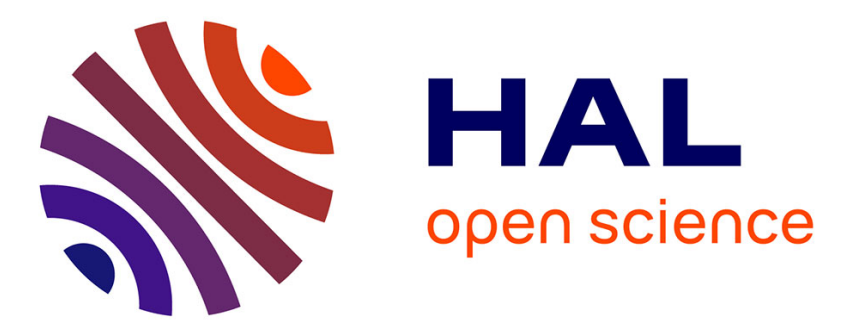

\title{
Non-hydrolytic sol-gel synthesis of polypropylene/TiO2 composites by reactive extrusion
}

\author{
Manon Besançon, Yanhui Wang, Noëllie Ylla, Valentin Cinquin, Hubert \\ Mutin, Johan Alauzun, Eliane Espuche, Véronique Bounor-Legaré
}

\section{- To cite this version:}

Manon Besançon, Yanhui Wang, Noëllie Ylla, Valentin Cinquin, Hubert Mutin, et al.. Non-hydrolytic sol-gel synthesis of polypropylene/TiO2 composites by reactive extrusion. Journal of Sol-Gel Science and Technology, 2021, 10.1007/s10971-021-05548-4 . hal-03246021v2

\section{HAL Id: hal-03246021 \\ https://hal.science/hal-03246021v2}

Submitted on 15 Nov 2021

HAL is a multi-disciplinary open access archive for the deposit and dissemination of scientific research documents, whether they are published or not. The documents may come from teaching and research institutions in France or abroad, or from public or private research centers.
L'archive ouverte pluridisciplinaire HAL, est destinée au dépôt et à la diffusion de documents scientifiques de niveau recherche, publiés ou non, émanant des établissements d'enseignement et de recherche français ou étrangers, des laboratoires publics ou privés. 


\title{
Non-hydrolytic sol-gel synthesis of polypropylene/ $/ \mathrm{TiO}_{2}$ composites by reactive extrusion
}

\author{
Manon Besançon ${ }^{1}$, Yanhui Wang ${ }^{2}$, Noëllie Ylla $^{1}$, Valentin Cinquin ${ }^{1}$, Hubert Mutin ${ }^{2}$, Johan \\ Alauzun $^{2}$, Eliane Espuche ${ }^{1}$, Véronique Bounor-Legaré ${ }^{1^{*}}$ \\ 1- Univ Lyon, Université Lyon1, UMR CNRS 5223, Ingénierie des Matériaux Polymères, Lyon, \\ F-69622, France \\ 2- Institut Charles Gerhardt, Université de Montpellier 2, CNRS UMR5253, Place Eugène \\ Bataillon, 34095 Montpellier cedex 5, France \\ *E-mail: veronique.bounor-legare@univ-lyon1.fr
}

\begin{abstract}
An original way to synthesise polypropylene/titanium dioxide $\left(\mathrm{PP} / \mathrm{TiO}_{2}\right)$ composites combining non-hydrolytic sol-gel chemistry and reactive extrusion was reported. The non-hydrolytic sol-gel reaction between titanium alkoxide as a titanium dioxide precursor and an acid anhydride as an oxygen donor at $240^{\circ} \mathrm{C}$ was first evaluated and optimised in an alkane liquid medium. $\mathrm{TiO}_{2}$ was present essentially in crystalline anatase form when synthesised in squalane with a domain size around $10 \mathrm{~nm}$. Based on these encouraging results, the synthesis was adapted to reactive extrusion that means at high temperature in molten viscous polypropylene and for short reaction times (few minutes maximum). The proof of concept was evidenced through the formation of amorphous $\mathrm{TiO}_{2}$ based inorganic domains of size around $1 \mu \mathrm{m}$ within the polymer matrix from the reaction between titanium isopropoxide and acetic anhydride. A condensation degree of $79 \%$ was obtained. To optimise the polymer/filler interface, titanium dioxide precursors and oxygen donors with different alkyl chain lengths were evaluated. Hexanoic anhydride as substituent of acetic anhydride and titanium tetrakis 2-ethylhexyloxide as substituent of titanium isopropoxide were used. The oxygen donor contribution appeared to be dominant for the particle dispersion state. The $\mathrm{PP} / \mathrm{TiO}_{2}$ composite synthesised from the reaction between titanium isopropoxide and hexanoic anhydride showed the narrowest $\mathrm{TiO}_{2}$ particle diameter distribution with a mean particle size around $700 \mathrm{~nm}$.
\end{abstract}

Keywords: non hydrolytic sol-gel, reactive extrusion, titanium dioxide, polyolefin 
Organic/inorganic hybrids and nanocomposite materials have drawn considerable attention due to their potential to enhance structural and functional properties of polymer-based systems. The key parameter for such improvement is the controlled dispersion of inorganic nanofillers. Actually, when well-dispersed, a small amount of inorganic fillers with nanometre size can significantly improve the composite properties, such as mechanical performance [1], flame retardance [2] or gas permeability [3] while maintaining transparency.

The common way to elaborate nanocomposites is the 'top-down' approach, i.e. the dispersion of preformed nanometre-sized fillers into the polymer. These fillers usually consist of elementary nanoparticles forming agglomerates with dimensions up to the micrometre scale. To reach dispersion at the nanometre scale, interactions between particles must be broken by thermomechanical strain. Moreover, modification of the filler and/or the polymer matrix must often be carried out to promote filler/matrix interactions $[4,5]$. Despite these approaches, the dispersion of individual nanofillers is usually difficult to achieve, particularly in the case of hydrophilic nanofillers and hydrophobic polymers such as polyolefins because of their poor compatibility. In addition, another obstacle to the development of nanocomposites is the increasing concerns about nanoparticle manipulation [6]. To overcome these limitations, a 'bottom-up' approach has been developed for the past 20 years, combining reactive extrusion and sol-gel chemistry [7]. Up to now, this approach has been exclusively centred on the hydrolytic sol-gel process. Several works have shown the possibility of generating in situ titanium dioxide nanoparticles in a PP matrix $[8,9]$. Kaneko et al. [8] proposed a strategy to synthesise $\mathrm{PP} / \mathrm{TiO}_{2}$ nanocomposites based on a catalysed in situ solgel reaction during melt mixing. More specifically, $\mathrm{PP} / \mathrm{TiO}_{2}$ nanocomposites were obtained by melt mixing PP powder preliminarily impregnated with different titanium alkoxides (titanium $n$-butoxide, titanium ethoxide or titanium isopropoxide) and a catalytic component (bis(1,2,2,6,6-pentamethyl-4piperidyl) sebacate or citric acid). The dispersion of the obtained nanoparticles with size below $10 \mathrm{~nm}$ required $6 \mathrm{~h}$ of impregnation time and the presence of the catalytic component. Another study dedicated to $\mathrm{PP} / \mathrm{TiO}_{2}$ synthesis by in situ sol-gel chemistry was conducted by Bounor-Legaré et al. $[9,10]$. They demonstrated the influence of water incorporated during reactive extrusion on the final nanocomposite morphologies. Titanium $n$-butoxide was incorporated in the molten PP during extrusion performed at $200^{\circ} \mathrm{C}$. Without water incorporation, the formation of small titanium oxoorgano clusters was favoured, creating an inorganic network consisting of nanometric fillers in the matrix. A post-treatment consisting of the immersion of the obtained $\mathrm{PP} / \mathrm{TiO}_{2}$ nanocomposite in water at $80^{\circ} \mathrm{C}$ for $72 \mathrm{~h}$ allowed a better conversion rate, superior to $95 \%$. The particle diameter obtained after a post-treatment remained below $10 \mathrm{~nm}$. It was shown that the addition of water in the extruder at a high temperature also enhanced the conversion rate of sol-gel reactions and the condensation degree of $\mathrm{TiO}_{2}$ particles, but favoured nanoparticle agglomeration. The size of these agglomerates was approximately $200 \mathrm{~nm}$. The surface of such inorganic phase presented hydroxyl groups and consequently had a poor compatibility with the hydrophobic polypropylene matrix.

The non-hydrolytic sol-gel (NHSG) process has been extensively studied during the past 30 years and can overcome some limitations of aqueous processes, including the poor dispersion of particles in an organic medium [11]. The specificities of NHSG chemistry are the use of an organic oxygen donor instead of water and the ability to control the shape and the size of nanoparticles [12]. The NHSG process takes place in non-aqueous media and is based on thermoactivated reactions between a metal or a silicon precursor and an oxygen donor other than water. NHSG routes to oxides have been extensively studied and reviewed $[13,14]$. Three main routes can be highlighted: the alkyl 
halide elimination route involving the condensation between metal alkoxides and metal halides (eq. 1), the ether elimination route by a reaction between two metal alkoxides (eq. 2 ) and finally the ester elimination process involving the reaction between metal carboxylates and metal alkoxides (eq.3).

$$
\begin{aligned}
& \equiv M-C l+R-O-M \equiv-\longrightarrow M-O-M \equiv+R-C l \\
& \equiv M-O-R+R^{\prime}-O-M \equiv \longrightarrow \equiv M-O-M \equiv+R-O-R^{\prime} \\
& \equiv M-O-C(=0) R^{\prime}+R-O-M \equiv \longrightarrow \equiv M-O-M \equiv+R-O-C(=0) R^{\prime}
\end{aligned}
$$

One of the most widely explored approaches to synthesise titanium dioxide nanoparticles was the use of metal halides as a precursor via an alkyl halide elimination route. Trentler et al. [15] were the first to describe the synthesis of crystalline anatase nanoparticles based on the reaction of titanium tetrachloride with titanium isopropoxide $\mathrm{Ti}\left(\mathrm{O}^{\mathrm{i}} \mathrm{Pr}\right)_{4}$ in trioctylphosphine oxide/heptadecane at $300^{\circ} \mathrm{C}$. The reaction was completed within $5 \mathrm{~min}$ and led to the formation of anatase nanoparticles with crystalline domains diameter below $10 \mathrm{~nm}$. Niederberger et al. [16] synthesised anatase nanoparticles from the reaction between titanium tetrachloride and benzyl alcohol at $60^{\circ} \mathrm{C}$ or $100^{\circ} \mathrm{C}$ for $8 \mathrm{~h}$ followed by an aging for several days. Recently, Wang et al. [17] described the synthesis of mesoporous $\mathrm{TiO}_{2}$ by a reaction between $\mathrm{Ti}\left(\mathrm{O}^{\mathrm{i}} \mathrm{Pr}\right)_{4}$ and acetic anhydride $\left(\mathrm{Ac}_{2} \mathrm{O}\right)$ at $200^{\circ} \mathrm{C}$ for $12 \mathrm{~h}$. Many publications have described the synthesis of $\mathrm{TiO}_{2}$ nanoparticles in solvent medium, but up to now only a few studies have focused on the in situ synthesis of particles by the NHSG process in a polymer matrix. Morselli et al. [18] synthesised poly(methyl methacrylate)- $\mathrm{TiO}_{2}$ nanocomposite by an in situ non-hydrolytic sol-gel reaction between titanium tetrachloride and benzyl alcohol. The polymer matrix was dissolved in benzyl alcohol at $70^{\circ} \mathrm{C}$ and then the titanium dioxide precursor was added at room temperature. After 15 minutes, the solution was heated at $70^{\circ} \mathrm{C}$ or $100^{\circ} \mathrm{C}$ for $24 \mathrm{~h}$. Welldistributed spherical anatase particles of about $30 \mathrm{~nm}$ were obtained.

To the best of our knowledge, the use of NHSG in molten polymers during an extrusion process remains unexplored in the literature and could represent an elegant way to synthesise nanocomposites without the manipulation of nanoparticles or solvent. Specific properties such as mechanical barriers, for example, can be envisioned while maintaining transparency. The aim of this article was thus to propose a new route to generate $\mathrm{TiO}_{2}$ nanoparticles in a bottom-up approach combining NHSG reactions and reactive extrusion. For that goal, the synthesis of $\mathrm{TiO}_{2}$ particles was first performed at $240^{\circ} \mathrm{C}$ for $1 \mathrm{~h}$ from titanium isopropoxide and acetic anhydride $\left(\mathrm{Ac}_{2} \mathrm{O}\right)$ in a model apolar liquid medium in order to evaluate the reactivity. Reactions were then transposed into molten polymer medium to synthesise $\mathrm{PP} / \mathrm{TiO}_{2}$ composites for an expected filler concentration of $5 \mathrm{wt} \%$. Then, in order to improve the dispersion state of synthesised $\mathrm{TiO}_{2}$ particles in the hydrophobic polymer matrix, another titanium dioxide precursor and an acid anhydride with longer alkyl chains than $\mathrm{Ac}_{2} \mathrm{O}$ were investigated. By-products of NHSG reactions were studied and the morphology and linear viscoelastic behaviour of composites in the molten state were investigated in order to evaluate the influence of the different reactants on particle size and dispersion.

\section{Experimental part Chemicals}

The polypropylene (PP «Moplen HP500N») used in this work was provided by LyonDellBasell. The melt flow rate was $12 \mathrm{~g}$ in $10 \mathrm{~min}\left(230^{\circ} \mathrm{C} / 2.16 \mathrm{~kg}\right)$. Squalane $(98 \%)$ was purchased from Alfa 
Aesar. $\mathrm{TiO}_{2}$ Aeroxide P25 nanoparticles with a primary particle size of about $21 \mathrm{~nm}$ were purchased

2 from Sigma Aldrich and used to prepare the $\mathrm{PP} / \mathrm{TiO}_{2}$ nanocomposite reference. The structure of the

3 reactants used to in situ synthesise the $\mathrm{TiO}_{2}$ nanoparticles were presented in Table 1. Titanium (IV)

4 isopropoxide $\left(\mathrm{Ti}\left(\mathrm{O}^{\mathrm{P} P r}\right)_{4}\right) 97 \%$, tetrakis 2-ethylhexyl orthotitanate $\mathrm{Ti}(2-\mathrm{OEtHex})_{4} 97 \%$ and hexanoic

5 anhydride $\left(\mathrm{Hex}_{2} \mathrm{O}_{3}\right) 97 \%$ were purchased from $\mathrm{ABCR}$. Acetic anhydride $\left(\mathrm{Ac}_{2} \mathrm{O}\right) \geq 99 \%$ was purchased

6 from Carlo Erba. All chemicals were used without further purification. Some of their properties are

7 depicted in Table 1.

9 Table 1 - Structure and selected properties of titanium dioxide precursors and acid anhydrides

\begin{tabular}{|c|c|c|c|c|}
\hline & $\begin{array}{c}\text { Titanium isopropoxide } \\
\qquad \mathrm{Ti}\left(\mathrm{O}^{\mathrm{i} P r}\right)_{4}\end{array}$ & $\begin{array}{l}\text { Tetrakis 2-ethylhexyloxide } \\
\text { orthotitanate } \\
\text { Ti(2-OEtHex })_{4}\end{array}$ & $\begin{array}{l}\text { Acetic anhydride } \\
\qquad \mathrm{Ac}_{2} \mathrm{O}\end{array}$ & $\begin{array}{c}\text { Hexanoic anhydride } \\
\mathrm{Hex}_{2} \mathrm{O}_{3}\end{array}$ \\
\hline \multicolumn{5}{|l|}{$\begin{array}{l}\text { Chemical } \\
\text { structure }\end{array}$} \\
\hline $\begin{array}{c}\text { Molar mass } \\
\left(\mathrm{g} \mathrm{mol}^{-1}\right)\end{array}$ & 284.22 & 564.75 & 102.09 & 214.30 \\
\hline $\begin{array}{l}\text { Boiling point } \\
\left({ }^{\circ} \mathrm{C}\right)\end{array}$ & 232 & 248 & 140 & 250 \\
\hline
\end{tabular}

10

11

\section{$\mathrm{TiO}_{2}$ synthesis in squalane}

These syntheses were carried out in a glovebox under argon atmosphere $(<10 \mathrm{ppm}$ of water and $\left.\mathrm{O}_{2}\right)$. $\mathrm{Ti}\left(\mathrm{O}^{\mathrm{i} P r}\right)_{4}(1.57 \mathrm{~g}, 5.5 \mathrm{mmol}), \mathrm{Ac}_{2} \mathrm{O}(1.12 \mathrm{~g}, 11.0 \mathrm{mmol})$ and $10 \mathrm{~mL}(8.1 \mathrm{~g})$ of squalane were mixed in a stainless steel digestion vessel equipped with a PTFE (polytetrafluoroethylene) lining (23 $\mathrm{mL}$ ). Then, the sealed autoclave was heated in an oven at $240^{\circ} \mathrm{C}$ for $1 \mathrm{~h}$ under autogenous pressure. The temperature was chosen according to extrusion process temperature. After this reaction step, the resulting white precipitate was washed with $\mathrm{CHCl}_{3}(30 \mathrm{~mL}, 5$ times) and then acetone $(30 \mathrm{~mL}, 5$ times). The precipitate was dried under vacuum at room temperature and then ground into a fine white powder.

\section{$\mathrm{TiO}_{2}$ synthesis in molten polypropylene}

A PP $/ \mathrm{TiO}_{2}$ nanocomposite reference with 5 wt\% fillers was prepared in a Haake Plasticorder ${ }^{\circledR}$ intensive batch mixer equipped with two Rheomix 600 roller rotors running in a counter rotating way. The rotor speed was set at $50 \mathrm{rpm}$. Commercial $\mathrm{TiO}_{2}$ was incorporated in molten polypropylene at $200^{\circ} \mathrm{C}$. This temperature was maintained for 5 minutes then the temperature was gradually increased from $200^{\circ} \mathrm{C}$ to $240^{\circ} \mathrm{C}$ ( with a heating rate of $10^{\circ} \mathrm{C} \mathrm{min}$ ). Finally, the blend was mixed for 15 minutes after the introduction of reactants.

All other composite materials were prepared using a co-rotating twin screw extruder (Leistritz ZSE18, D = $18 \mathrm{~mm}, \mathrm{~L} / \mathrm{D}=60$ ). The screw profile was represented in Figure 1. It was composed of conveying elements (GFA and GFF), two reverse elements (one for the PP melting before reactants incorporation and the other one before the extraction of by-products by vacuum pumping) (GFA-L), kneading (KB) and mixing elements (MB). The screw speed was set at $100 \mathrm{rpm}$. 
Temperature of each block can be adjusted independently. Polypropylene was incorporated in the block 0 ( $B 0$ in Figure 1 ) at $200^{\circ} \mathrm{C}$ and with a feed rate $Q=1 \mathrm{~kg} \mathrm{~h}^{-1}$. Depending on the reactants nature and reactivity, two strategies of incorporation were followed (specified in Table 2). First, for the samples $\mathrm{Ti}\left(\mathrm{O}^{\mathrm{i}} \mathrm{Pr}\right)_{4}-\mathrm{Ac}_{2} \mathrm{O}, \mathrm{Ti}(\mathrm{OEtHex})_{4}-\mathrm{Ac}_{2} \mathrm{O}$ and $\mathrm{Ti}\left(\mathrm{O}^{\mathrm{i}} \mathrm{Pr}\right)_{4}-\mathrm{Hex}_{2} \mathrm{O}_{3}$, a pre-mixed strategy was required. In those cases, the titanium dioxide precursor and the oxygen donor were first mixed in a Schlenk tube under argon at room temperature for $1 \mathrm{~h}$. Then, this solution was injected in block 2 (B2 in Figure 1) of the extruder. For the reaction between $\mathrm{Ti}(\mathrm{OEtHex})_{4}$ and hexanoic anhydride (Table 2), hexanoic anhydride was injected directly into block 2 and Ti(2-OEtHex $)_{4}$ directly into block 3 using liquid pumps. After introduction of the reactants into the molten PP, the temperature was increased up to $240^{\circ} \mathrm{C}$ in block 4 . A vacuum pumping system was set up (B10 in Figure 1 ) in order to extract the byproducts. The sample was collected at the die exit and cooled under air flow. A hydrolytic reference was prepared by injecting only the titanium dioxide precursor $\mathrm{Ti}\left(\mathrm{O}^{\mathrm{P}} \mathrm{Pr}\right)_{4}$ into block 2 in order to confirm that titanium dioxide precursor hydrolysis was negligible in comparison with the NHSG reaction.

All reaction conditions were summarised in Table 2. Mass quantities of the introduced reactants were calculated to theoretically obtain $5 \mathrm{wt} \% \mathrm{TiO}_{2}$ in the final PP-based composite, assuming that the reaction was complete. Boiling points (bp) of expected by-products and temperature of the block B10 were also given in Table $\mathbf{2}$.

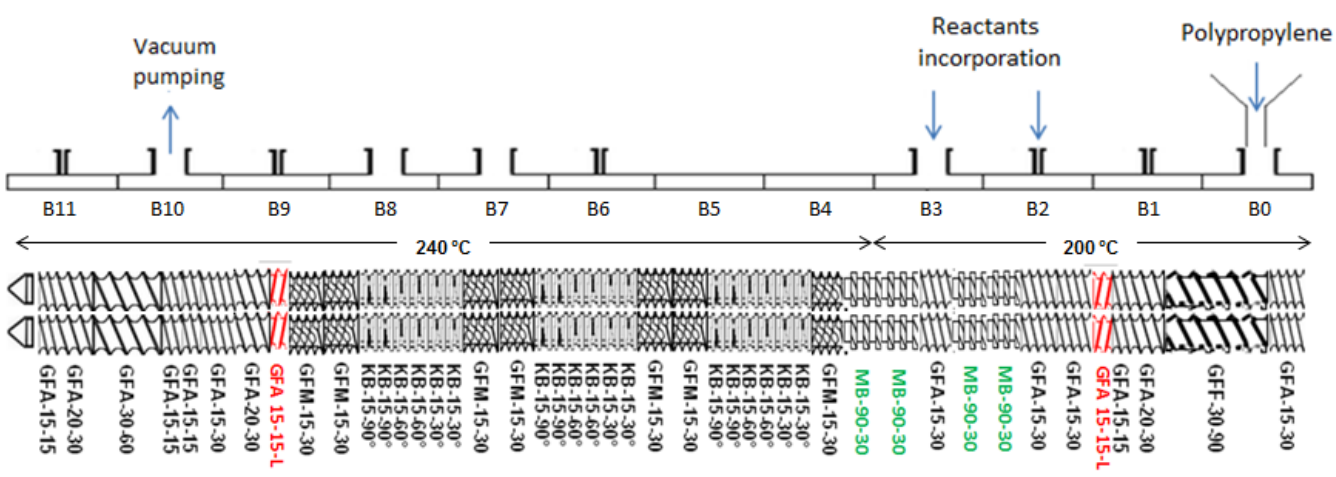

Figure 1 - Screw profile and localization of injection and by-products extraction points

Table 2 - Reaction conditions for the synthesis by reactive extrusion of $\mathrm{PP} / \mathrm{TiO}_{2}$ composites from different reactants and expected reaction by-products

\begin{tabular}{|c|c|c|c|c|c|c|}
\hline Sample & Precursor & O-donor ${ }^{a}$ & $\begin{array}{c}\text { Pre-mixing } \\
\text { strategy }\end{array}$ & Expected by-product & $\begin{array}{l}\text { Expected by- } \\
\text { product boiling } \\
\text { point }\left({ }^{\circ} \mathrm{C}\right)\end{array}$ & $\begin{array}{c}\text { Temperature } \\
\text { of } \mathrm{B} 10 \text { block } \\
\left({ }^{\circ} \mathrm{C}\right)\end{array}$ \\
\hline $\begin{array}{l}\text { Hydrolytic } \\
\text { reference }\end{array}$ & $\mathrm{Ti}\left(\mathrm{O}^{\mathrm{i}} \mathrm{Pr}\right)_{4}$ & / & / & / & / & 240 \\
\hline $\mathrm{Ti}\left(\mathrm{O}^{\mathrm{i}} \mathrm{Pr}\right)_{4}-\mathrm{Ac}_{2} \mathrm{O}$ & $\mathrm{Ti}\left(\mathrm{O}^{\mathrm{i}} \mathrm{Pr}\right)_{4}$ & $\mathrm{Ac}_{2} \mathrm{O}$ & Yes & Isopropyl acetate & 90 & 240 \\
\hline $\mathrm{Ti}(\mathrm{OEtHex})_{4}-\mathrm{Ac}_{2} \mathrm{O}$ & $\mathrm{Ti}(2-\mathrm{OEtHex})_{4}$ & $\mathrm{Ac}_{2} \mathrm{O}$ & Yes & 2-ethylhexyl acetate & 199 & 240 \\
\hline $\mathrm{Ti}\left(\mathrm{O}^{\mathrm{i}} \mathrm{Pr}\right)_{4}-\mathrm{Hex}_{2} \mathrm{O}_{3}$ & $\mathrm{Ti}\left(\mathrm{O}^{\mathrm{i}} \mathrm{Pr}\right)_{4}$ & $\mathrm{Hex}_{2} \mathrm{O}_{3}$ & Yes & Isopropyl hexanoate & 172 & 240 \\
\hline $\mathrm{Ti}(\mathrm{OEtHex})_{4}-\mathrm{Hex}_{2} \mathrm{O}_{3}$ & $\mathrm{Ti}(2-\mathrm{OEtHex})_{4}$ & $\mathrm{Hex}_{2} \mathrm{O}_{3}$ & No & 2-ethylhexyl hexanoate & 265 & 280 \\
\hline
\end{tabular}

\footnotetext{
${ }^{\mathrm{a}} 2$ equivalents relative to the precursor
} 
Concerning by-product elimination, two cases were encountered depending on the boiling point. Either all by-products was removed from the composite thanks to vacuum pump degassing (mainly for by-products presenting the lowest boiling points), or residual by-products remained in the composite (due to their high boiling point). In this last case, in order to quantify the final reaction advancements, the residual by-products were extracted by Soxhlet extraction. In detail, $8 \mathrm{~g}$ of nanocomposite sample was grounded into a powder and placed in the Soxhlet device. The solvent used for this purification step was ethyl acetate and the extraction took place at $110^{\circ} \mathrm{C}$ for $72 \mathrm{~h}$.

\section{Characterisation techniques}

${ }^{1} \mathrm{H}$ NMR spectroscopy analyses of the reaction medium were performed with samples in solution in deuterated chloroform $\left(\mathrm{CDCl}_{3}\right)$ using a Bruker Avance III $400 \mathrm{MHz}$ spectrometer.

Thermogravimetric analyses (TGA) of polymer and extruded composites were performed with the TA Q600 of TA Instruments. All the experiments were carried out under a helium atmosphere at a flow rate of $60 \mathrm{~mL} \mathrm{~min}^{-1}$. Samples were heated from room temperature up to $600^{\circ} \mathrm{C}$ with a heating rate of $10^{\circ} \mathrm{C} \mathrm{min}^{-1}$.

Reactants and by-products present in the composites were identified by coupling techniques based on thermal desorption analysis (TDA), gas chromatography (GC) and mass spectroscopy (MS). TDA experiments were performed with a Turbo Matrix 350 instrument of Perkin Elmer under an inert helium atmosphere at the flow rate of $1 \mathrm{~mL} \mathrm{~min}$. Nanocomposite samples were heated to $200^{\circ} \mathrm{C}$ and the temperature was maintained for $10 \mathrm{~min}$. The released volatiles were transferred to a gas chromatograph Clarus 680 of Perkin Elmer and a mass spectrometer Clarus SQ 8T of Perkin Elmer. Liquid extracted by-products were analysed by GC-MS coupling, with the same equipment as mentioned before.

X-ray photoelectron (XPS) spectroscopy measurements were carried out using a PHI Quantera SXM spectrometer with a non-monochromatised AIKa source. XPS spectra were collected at a $45^{\circ}$ take-off angle between the sample and the analyser. The deconvolution of the spectra was carried out using Multipak (PHI) software. Analyses were operated at energy of $280 \mathrm{eV}$ for survey spectra and $140 \mathrm{eV}$ for high resolution spectra.

The powder X-ray diffraction (XRD) pattern of $\mathrm{TiO}_{2}$ particles synthesised in solvent medium was collected with a PANalytical $X^{\prime}$ Pert Pro MPD diffractometer using $\mathrm{Cu}$ K $\alpha$ radiation ( $\lambda=1.54 \AA$ ). Data were collected from $15^{\circ}$ to $70^{\circ}$ in order to evidence the formation of nanocrystals. The crystalline structure of $\mathrm{PP} / \mathrm{TiO}_{2}$ composites was analysed with the same equipment on composites ground to fine powder. Data were collected from $5^{\circ}$ to $50^{\circ}$ in order to obtain the whole XRD pattern of polypropylene or from $1^{\circ}$ to $6^{\circ}$ to provide spectra at low angles.

Raman spectroscopy analyses were also conducted to investigate the amorphous or crystalline nature of $\mathrm{TiO}_{2}$ particles synthesised in molten polypropylene and in the last case, for determining the type of crystalline structure. Raman spectra were obtained with a Horiba Jobin Yvon LabRAM ARAMIS spectrometer equipped with a CCD detector cooled by a Peltier module. Two lasers were used: $473 \mathrm{~nm}$ and $633 \mathrm{~nm}$.

Scanning electron microscopy (SEM) images of $\mathrm{TiO}_{2}$ particles synthesised in alkane medium were obtained with a Hitachi S-4800 electron microscope by secondary electron detection mode. The SEM observations of $\mathrm{PP} / \mathrm{TiO}_{2}$ composites were performed on a FEI Quanta 250 FEG microscope with a voltage of $10 \mathrm{kV}$ by backscattered electron analysis in order to obtain a good contrast between the polymer matrix and titanium dioxide particles. Observed sections were prepared by cryoultramicrotomy at $-110^{\circ} \mathrm{C}$. Particles diameters were determined using Image J software. Transmission 
electron microscopy (TEM) observations were performed on a Philips CM120 microscope with an accelerated voltage of $120 \mathrm{kV}$. Ultrathin sections were made at $-110^{\circ} \mathrm{C}$ using a Leica cryoultramicrotome equipped with a diamond knife. The thickness of sections was about $80 \mathrm{~nm}$.

Rheological behaviours of the PP matrix and nanocomposites were analysed in order to investigate the in situ generated particles effect on the linear viscoelastic behaviour of nanocomposites. Measurements were performed in linear dynamic mode of shearing on a rheometer ARES G2 of TA Instruments. Parallel plate geometry with a diameter of $25 \mathrm{~mm}$ was used. Analyses were carried out at $200^{\circ} \mathrm{C}$ under a nitrogen atmosphere to prevent thermo-oxidative degradation of the samples. A constant deformation $(\gamma=5 \%)$ was chosen in the linear viscoelastic region and experiments were performed in the frequency range $10^{-2}<\omega\left(\operatorname{rad~s}^{-1}\right)<5.10^{2}$.

Size exclusion chromatography (SEC) analyses were performed on polypropylene and composites ground to fine powder with a Viscotek-Malvern Instrument equipped with a triple detector consisting of a refractive index detector, a viscosimeter and a light scattering detector, with a right-angle light scattering detector $\left(90^{\circ}\right)$ and a low-angle light scattering detector $\left(7^{\circ}\right)$. The polymer was dissolved in $1,2,4$ trichlorobenzene at $150^{\circ} \mathrm{C}$ and injected into Waters Styragel HT6E columns at a flow rate of $1 \mathrm{~mL} \mathrm{~min}$. The injection volume was $200 \mu \mathrm{L}$.

\section{Results and discussion}

\section{Non-hydrolytic sol-gel synthesis of $\mathrm{TiO}_{2}$ in a model medium}

The first objective of this work was to demonstrate the feasibility of the NHSG reaction in conditions as close as possible to extrusion process ones. To meet the specific conditions of reactive extrusion, NHSG reaction had to be carried out at a higher temperature than the polymer melting point. Furthermore, residence time in an extruder was a few minutes, so selected precursors and oxygen donors should be reactive enough to obtain a high degree of condensation. Although the use of titanium halide was the most explored route in conventional approaches, the use of this precursor was not possible in reactive extrusion because of the possible problem of corrosion of the barrel. Wang and colleagues [17] found that the reaction between $\mathrm{Ti}\left(\mathrm{O}^{\mathrm{i} P r}\right)_{4}$ and acetic anhydride in stoichiometric conditions at $200^{\circ} \mathrm{C}$ led after $12 \mathrm{~h}$ to mesoporous $\mathrm{TiO}_{2}$ in high yields. Based on this work, titanium alkoxides were selected as titanium dioxide precursors and acid anhydrides as oxygen donors, considering the specificities of reactive extrusion. A temperature of $200^{\circ} \mathrm{C}$ was suitable for reaction in molten polypropylene, but $12 \mathrm{~h}$ was an extremely long reaction time in comparison with the residence time in an extruder (few minutes). Thus, in this part dedicated to the study of reaction in model medium, the reaction temperature was fixed at $240^{\circ} \mathrm{C}$ in order to reduce the reaction time.

The reaction between the titanium isopropoxide and the acetic anhydride led to the formation of $\mathrm{TiO}_{2}$ by an ester elimination mechanism in two steps, involving a first step of acetoxylation (eq. 4) and a second step of condensation (eq. 5) [17]. The formed ester was the isopropyl acetate $\left(\mathrm{CH}_{3} \mathrm{COO}\right.$ 'Pr).

$$
\begin{aligned}
& \equiv \mathrm{Ti}-\mathrm{O}^{\mathrm{i}} \mathrm{Pr}+\left(\mathrm{CH}_{3} \mathrm{CO}\right)_{2} \mathrm{O} \rightarrow \equiv \mathrm{Ti}-\mathrm{OCOCH}{ }_{3}+\mathrm{CH}_{3} \mathrm{COO}^{\mathrm{i} P r} \\
& \equiv \mathrm{Ti}-\mathrm{O}^{\mathrm{i}} \mathrm{Pr}+\equiv \mathrm{Ti}-\mathrm{OCOCH}_{3} \rightarrow \equiv \mathrm{Ti}-\mathrm{O}-\mathrm{Ti} \equiv+\mathrm{CH}_{3} \mathrm{COO}^{\mathrm{P} r}
\end{aligned}
$$


In order to evaluate the kinetic of the first reaction step, $\mathrm{Ti}\left(\mathrm{O}^{\mathrm{i}} \mathrm{Pr}\right)_{4}$ and $\mathrm{Ac}_{2} \mathrm{O}$ were mixed without a solvent. According to the ${ }^{1} \mathrm{H} N M R$ analysis of the reaction medium in $\mathrm{CDCl}_{3}$ (Figure $\mathrm{S1}$ in $\mathrm{SI}$ ), the acetoxylation reaction was complete after 10 minutes of mixing at room temperature. Actually, there was no trace of acetic anhydride (characteristic signal at $\delta=2.22 \mathrm{ppm}$ ), only the presence of isopropyl acetate. Characteristic signals at $\delta=1.11 \mathrm{ppm}(1), \delta=1.89 \mathrm{ppm}(3)$ and $\delta=4.86 \mathrm{ppm}$ (2) were attributed to $\mathrm{H}$ atoms of isopropyl acetate in Figure $\mathbf{S} 1$ in SI. The broad signal at around $2 \mathrm{ppm}$ arose from acetate groups linked to $\mathrm{TiO}_{2}$ based-domains and broad signal at $1.15 \mathrm{ppm}$ arose from isopropoxide groups linked to $\mathrm{TiO}_{2}$ domains.

The reaction was carried out at $240^{\circ} \mathrm{C}$ for $1 \mathrm{~h}$ in squalane, an apolar solvent chosen as the model medium of the polyolefin. The white precipitate obtained after the reaction in squalane was washed and dried at room temperature. The average yield of recovered product was around $85 \%$ regarding the expected amount. The obtained powder was constituted of $\mathrm{TiO}_{2}$ particles with some residual acetoxy groups on the surface.

SEM images of the resulting powder (Figure 2) showed elongated primary nanoparticles with diameters below $10 \mathrm{~nm}$ assembled to form spherical secondary particles of a few micrometres. These results were similar to those of Wang et al. [17] for the $\mathrm{TiO}_{2}$ synthesis in squalane at $200^{\circ} \mathrm{C}$ for $12 \mathrm{~h}$.
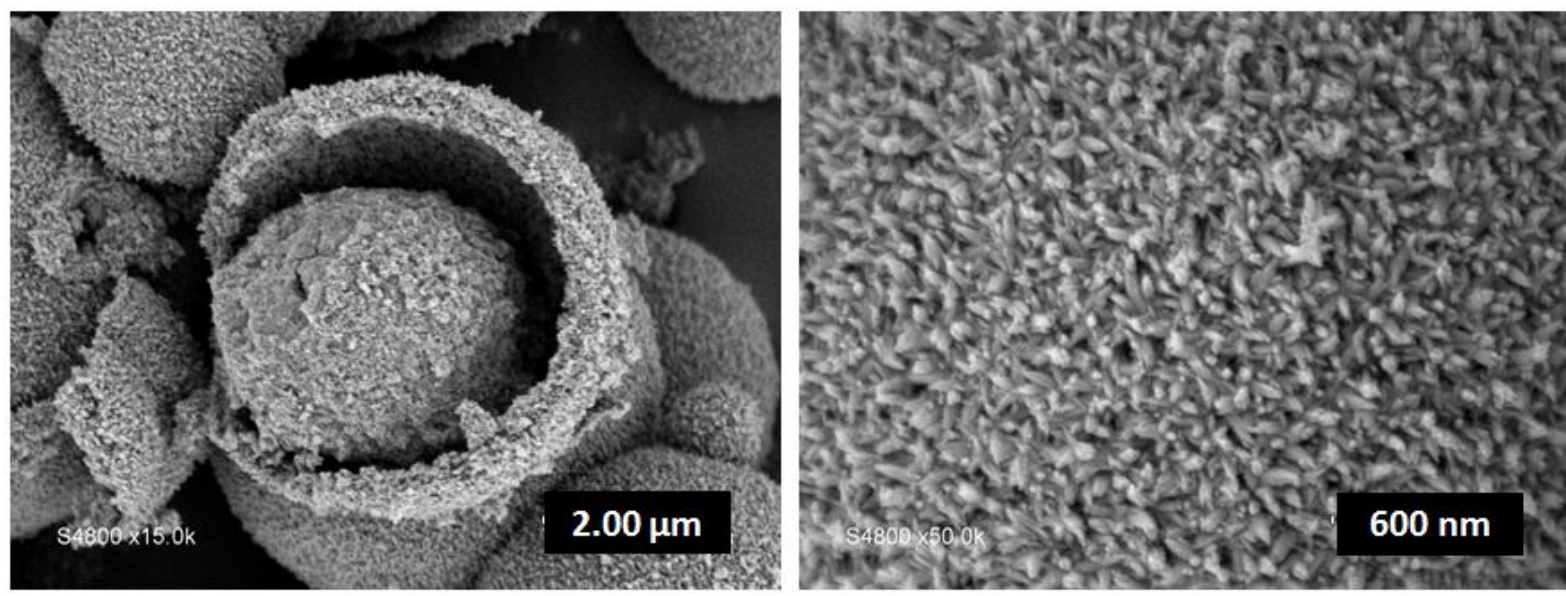

Figure 2 - SEM images of $\mathrm{TiO}_{2}$ particles synthesized from NHSG reaction between $\mathrm{Ti}\left(\mathrm{O}^{\mathrm{i}} \mathrm{Pr}\right)_{4}$ and $\mathrm{Ac}_{2} \mathrm{O}$ in squalane at $240^{\circ} \mathrm{C}$ for $1 \mathrm{~h}$

The XRD pattern of the $\mathrm{TiO}_{2}$ powder was presented in Figure 3 and showed the presence of diffraction peaks at $25.3^{\circ}, 37.8^{\circ}$ and $47.9^{\circ}$ corresponding respectively to (101), (004) and (200) crystal planes of anatase form of $\mathrm{TiO}_{2}$ (JCPDS 21-1272) [19]. The intense and narrower (004) reflection compared to the (200) reflection confirmed the presence of anisotropic nanoparticles elongated along the c-axis. The non-hydrolytic sol-gel reaction between $\mathrm{Ti}\left(\mathrm{O}^{\mathrm{i}} \mathrm{Pr}\right)_{4}$ and $\mathrm{Ac}_{2} \mathrm{O}$ provided at $240^{\circ} \mathrm{C}$ for $1 \mathrm{~h}$ an efficient route to synthesise anatase $\mathrm{TiO}_{2}$ in an apolar solvent. 


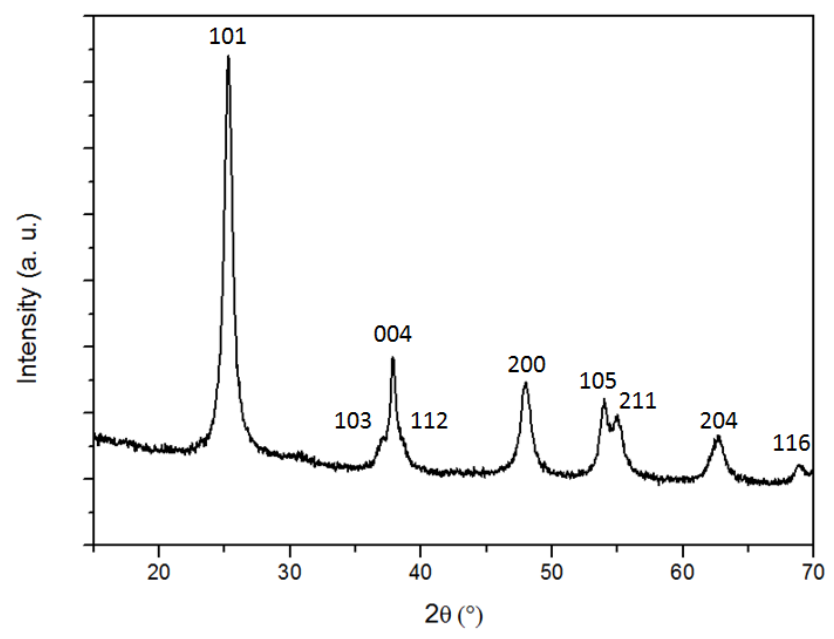

Figure 3 - Powder XRD pattern of $\mathrm{TiO}_{2}$ particles synthesized from NHSG reaction between $\mathrm{Ti}\left(\mathrm{O}^{\mathrm{i}} \mathrm{Pr}\right)_{4}$ and $\mathrm{Ac}_{2} \mathrm{O}$ in squalane at $240{ }^{\circ} \mathrm{C}$ for $1 \mathrm{~h}$

This study in squalane medium indicated that the non-hydrolytic acetic anhydride route allowed for preparing $\mathrm{TiO}_{2}$ particles in a short time if the reaction temperature was increased to $240^{\circ} \mathrm{C}$. This point was essential for considering the non-hydrolytic synthesis of $\mathrm{TiO}_{2}$ in situ in a molten polymer medium.

\section{Non-hydrolytic sol-gel synthesis of $\mathrm{TiO}_{2}$ in molten polypropylene}

\section{Nanocomposites based on $\mathrm{Ti}\left(\mathrm{O}^{\mathrm{i}} \mathrm{Pr}\right)_{4}$ and $\mathrm{Ac}_{2} \mathrm{O}$ as $\mathrm{TiO}_{2}$ precursors}

The aim of this part was transposing the NHSG reaction based on $\mathrm{Ti}\left(\mathrm{O}^{\mathrm{i}} \mathrm{Pr}\right)_{4}$ and $\mathrm{Ac}_{2} \mathrm{O}$ performed previously in a liquid alkane medium at $240^{\circ} \mathrm{C}$ to a molten polymer medium in the same range of temperature (the melting point of polypropylene is $160^{\circ} \mathrm{C}$ ), but for much shorter reaction times (a few minutes instead of $1 \mathrm{~h}$ ). The experimental conditions were reported in Table 2 line 2 and Figure 1.

The formation of $\mathrm{TiO}_{2}$ based particles was first demonstrated by electron microscopy analyses and the resulting morphology was compared to that of the $\mathrm{PP} / \mathrm{TiO}_{2}$ nanocomposite reference. On the SEM images of the $\mathrm{PP} / \mathrm{TiO}_{2}$ nanocomposite reference (Figure $4(\mathrm{a})$ ) and the extrudates $\mathrm{Ti}\left(\mathrm{O}^{\prime} \mathrm{Pr}\right)_{4}-\mathrm{Ac}_{2} \mathrm{O}$ (Figure $\mathbf{4}(\mathbf{b})$ ), the $\mathrm{TiO}_{2}$ particles appeared as bright areas. The nanocomposite reference exhibited some particle aggregates of a few micrometres, but the majority of particles were assembled in smaller well-dispersed aggregates, which were also visible on the TEM image of this sample (Figure 4(c)). For the $\mathrm{Ti}\left(\mathrm{O}^{\prime} \mathrm{Pr}\right)_{4}-\mathrm{Ac}_{2} \mathrm{O}$ composite, it appeared that particles were also well-distributed. The mean Feret's diameters of the dispersed particles were determined with the Image J software on the SEM images of the composites. The mean diameter of aggregates in the $\mathrm{PP} / \mathrm{TiO}_{2}$ nanocomposite reference was about $670 \mathrm{~nm}$. For the in situ synthesised $\mathrm{Ti}\left(\mathrm{O}^{\mathrm{i}} \mathrm{Pr}\right)_{4}-\mathrm{Ac}_{2} \mathrm{O}$ composite, the mean size was about $1 \mu \mathrm{m}$. Finally, the TEM image of $\mathrm{Ti}\left(\mathrm{O}^{\mathrm{i}} \mathrm{Pr}\right)_{4}-\mathrm{Ac}_{2} \mathrm{O}$ composite (Figure 4(d)) highlighted the presence of smaller particles, below $100 \mathrm{~nm}$ in diameter, not included in the mean diameter calculation.

In order to check that formed particles were not the result of the hydrolysis-condensation reactions of $\mathrm{Ti}\left(\mathrm{O}^{\mathrm{i} P r}\right)_{4}$, TEM micrographs of the hydrolytic reference (Table 2 line 1) (Figure 4(e)) were compared with the TEM micrograph of the extrudate $\mathrm{Ti}\left(\mathrm{O}^{\mathrm{i}} \mathrm{Pr}\right)_{4}-\mathrm{Ac}_{2} \mathrm{O}$. No particles were observed at 
this scale in the hydrolytic reference sample, meaning that hydrolytic sol-gel reaction of $\mathrm{Ti}\left(\mathrm{O}^{\mathrm{i}} \mathrm{Pr}\right)_{4}$ was negligible in comparison with non-hydrolytic sol-gel reaction between $\mathrm{Ti}\left(\mathrm{O}^{\mathrm{i}} \mathrm{Pr}\right)_{4}$ and $\mathrm{Ac}_{2} \mathrm{O}$ in the present processing conditions.


Figure 4 - SEM images of (a) PP/TiO ${ }_{2}$ nanocomposite reference ( $5 \mathrm{wt} \%$ ) and (b) $\mathrm{Ti}\left(\mathrm{O}^{\mathrm{i}} \mathrm{Pr}\right)_{4}-\mathrm{Ac}_{2} \mathrm{O}$ composite synthesized by reactive extrusion (5 wt \%) ; TEM images of (c) $\mathrm{PP} / \mathrm{TiO}_{2}$ nanocomposite reference $(5 \mathrm{wt} \%)$, (d) $\mathrm{Ti}\left(\mathrm{O}^{\mathrm{i}} \mathrm{Pr}\right)_{4}-\mathrm{Ac}_{2} \mathrm{O}$ composite synthesized by reactive extrusion ( $5 \mathrm{wt} \%$ ) and (e) hydrolytic reference from the incorporation of $\mathrm{Ti}\left(\mathrm{O}^{\mathrm{i}} \mathrm{Pr}\right)_{4}$ in molten polypropylene

As the in situ formation of $\mathrm{TiO}_{2}$ based particles from the non-hydrolytic sol-gel reaction between $\mathrm{Ti}\left(\mathrm{O}^{\prime} \mathrm{Pr}\right)_{4}$ and $\mathrm{Ac}_{2} \mathrm{O}$ in the polypropylene matrix was validated, the next step focused on the analysis of the reaction by-products, the extent of the reaction, the condensation degree determined by XPS analysis and finally the particle structure (amorphous or crystalline) elucidated by Raman spectroscopy and XRD.

During the synthesis by reactive extrusion of $\mathrm{Ti}\left(\mathrm{O}^{\mathrm{i}} \mathrm{Pr}\right)_{4}-\mathrm{Ac}_{2} \mathrm{O}$ composite, no by-products were recovered thanks to the vacuum pumping system. Moreover TDA-GC-MS coupling analysis (Figure S2 in SI) indicated that there were no remaining by-products in the composite. The only detectable signal on the chromatograph was the water present in the helium flow. No trace of isopropyl acetate was detectable. Actually, as the boiling point of this expected by-product was $90^{\circ} \mathrm{C}$ and thus low compared to reactive extrusion temperature, so it may have evaporated as soon as created. 
These first analyses were completed by TGA characterisation on the extrudates, which were compared to the thermograms of the pure polypropylene and reagents, respectively. It could have been clearly observed on the thermograms of Figure 5 that $\mathrm{Ac}_{2} \mathrm{O}$ had totally evaporated before $250^{\circ} \mathrm{C}$. For $\mathrm{Ti}\left(\mathrm{O}^{\mathrm{P}} \mathrm{Pr}\right)_{4}, 20 \mathrm{wt} \%$ of the inorganic residue was observed at a high temperature, corresponding to the expected rate of $\mathrm{TiO}_{2}$ particles formed by calcination. The thermogram of $\mathrm{Ti}\left(\mathrm{O}^{\mathrm{i}} \mathrm{Pr}\right)_{4}-\mathrm{Ac}_{2} \mathrm{O}$ composite did not display any mass losses before $300^{\circ} \mathrm{C}$, confirming the absence of residual reactants in the composite. The thermogram also indicated a slight weight loss (1.6 wt\%) between $300^{\circ} \mathrm{C}$ and $350^{\circ} \mathrm{C}$, which could have arisen from the creation of isopropyl acetate due to the condensation reactions of residual groups at the surface of $\mathrm{TiO}_{2}$ particles [17]. Polypropylene degradation typically occurs between $310^{\circ} \mathrm{C}$ and $450^{\circ} \mathrm{C}[20,21]$. Thermogravimetric analyses of extruded polypropylene and the $\mathrm{Ti}\left(\mathrm{O}^{\mathrm{i}} \mathrm{Pr}\right)_{4}-\mathrm{Ac}_{2} \mathrm{O}$ composite showed that PP degradation took place in the same temperature range. The degradation started at a higher temperature for the composite than for the neat polypropylene. The presence of metal could have influenced the degradation behaviour of the polymer. For example, the temperature of polypropylene thermal degradation was lower with the presence of copper than for the neat polymer [22]. However, in numerous studies, the presence of $\mathrm{TiO}_{2}$ particles allowed for improving the thermal stability of polypropylene [23,24]. Finally, the residue value measured at high temperature (above $500^{\circ} \mathrm{C}$ ) indicated the amount of inorganic species, equal to $5.3 \mathrm{wt} \%$, which was in good agreement with the theoretical expected one of $5 \mathrm{wt} \%$.

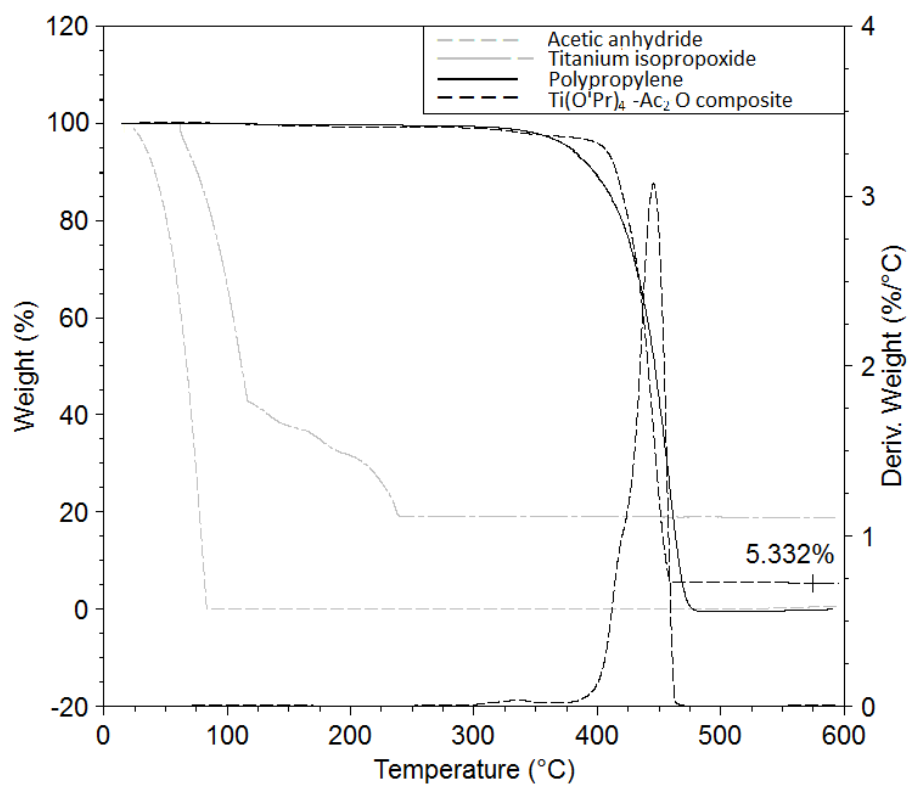

Figure 5 - TGA thermograms obtained under helium atmosphere of extruded polypropylene, $\mathrm{Ti}\left(\mathrm{O}^{\mathrm{i}} \mathrm{Pr}\right)_{4}$ and $\mathrm{Ac}_{2} \mathrm{O}$ reagents and $\mathrm{Ti}\left(\mathrm{O}^{\mathrm{i}} \mathrm{Pr}\right)_{4}-\mathrm{Ac}_{2} \mathrm{O}$ composite, heating rate $=10^{\circ} \mathrm{C} / \mathrm{min}$

The atomic concentrations of the individual elements were determined by XPS measurements for polypropylene and $\left.\mathrm{Ti}^{(} \mathrm{O}^{\mathrm{P}} \mathrm{Pr}\right)_{4}-\mathrm{Ac}_{2} \mathrm{O}$ composite (Table 3). Based on the morphological observation, we postulated a homogeneous repartition of the inorganic domains in the polypropylene matrix and thus we considered the overall composition similar to the surface composition.

Table 3 - Atomic composition \% according to XPS analysis for polypropylene and in situ synthesized $\mathrm{Ti}\left(\mathrm{O}^{\mathrm{i}} \mathrm{Pr}\right)_{4}-\mathrm{Ac}_{2} \mathrm{O}$ composite 


\begin{tabular}{lccc}
\hline & $\mathrm{C}$ & $\mathrm{O}$ & $\mathrm{Ti}$ \\
\hline $\mathrm{PP}$ & 100 & - & - \\
$\mathrm{PP} / \mathrm{TiO}_{2}\left(\mathrm{Ti}\left(\mathrm{O}^{\mathrm{P}} \mathrm{Pr}\right)_{4}-\mathrm{Ac}_{2} \mathrm{O}\right)$ & 99.1 & 0.7 & 0.2 \\
\hline
\end{tabular}

In the polypropylene reference, the only element found was carbon. Its peak was detected at $285 \mathrm{eV}$ and corresponds to aliphatic carbon C(1s) [25]. In the case of the in situ PP/TiO ${ }_{2}$ composite, C, $\mathrm{O}$ and $\mathrm{Ti}$ were detected, as expected. The ratio between $\mathrm{Ti}$ and $\mathrm{O}$ was different from the expected ratio of a $\mathrm{TiO}_{2}$ contribution. Indeed, for a titanium contribution of $0.2 \%$, the expected oxygen concentration would have been $0.4 \%$, which was significantly different from the effective oxygen concentration that was measured: $0.7 \%$. Three reasons could have explained this difference: the measurement uncertainty, the presence of pollution on the composite surface and, as expected, the presence of alkoxy groups on the surface of the particles due to incomplete condensation. In a publication by Bahloul et al. [26], a PP/anatase $\mathrm{TiO}_{2}$ composite with 9 wt\% fillers was analysed by XPS and the chemical composition ratio of the sample $(99.6 \% \mathrm{C} ; 0.3 \% \mathrm{O} ; 0.1 \% \mathrm{Ti})$ was approximately the same as the results obtained here.

XPS analysis provided also information about the condensation degree of synthesised titanium dioxide by quantifying Ti-O-Ti bonds in relation to Ti-O-C or Ti-O-H bonds. A detailed analysis of the $\mathrm{O}(1 \mathrm{~s})$ spectrum of the $\mathrm{PP} / \mathrm{TiO}_{2}$ composite (Figure 6) allowed us to determine the different environments of oxygen atoms in the created nanoparticles. The deconvolution of the O(1s) peak showed that two contributions could be distinguished. The first peak at $529.9 \mathrm{eV}$ was assigned to Ti$\mathrm{O}-\mathrm{Ti}$ and the second peak at $531.8 \mathrm{eV}$ to $\mathrm{Ti}-\mathrm{O}-\mathrm{H}$ or $\mathrm{Ti}-\mathrm{O}-\mathrm{C}[26-31]$. The condensation degree was determined by the respective area of these peaks. The proportion of Ti-O-Ti bonds was associated with the condensation degree. Indeed, $65 \%$ of oxygen atoms were involved in Ti-O-Ti bonds and $35 \%$ in $\mathrm{Ti}-\mathrm{O}-\mathrm{C}$ or $\mathrm{Ti}-\mathrm{O}-\mathrm{H}$ bonds, which corresponded to the formula Ti(O) $)_{1.58}(\mathrm{OR})_{0.84}$. The condensation degree was therefore estimated at $79 \%$. The method used to determine the condensation degree was detailed hereafter.

If we consider that $\mathrm{TiO}_{2}$ was the formula for a complete condensation (100\%) and that $\mathrm{Ti}(\mathrm{OR})_{4}$ was the formula for a non-condensed titanium atom (condensation degree equal to $0 \%$ ), a condensation degree of $50 \%$ corresponded to the formula $\mathrm{Ti}(\mathrm{O})_{2-x}(\mathrm{OR})_{2 x}$. Consequently, the determined percent of $\mathrm{O}$ atoms included in Ti-O-Ti environment by XPS analysis was equal to (2$\mathrm{x}) /((2-\mathrm{x})+2 \mathrm{x})$. The condensation degree $(C D)$ was then obtained by the following equation: $C D=$ $100 *(2-x) / 2$ 


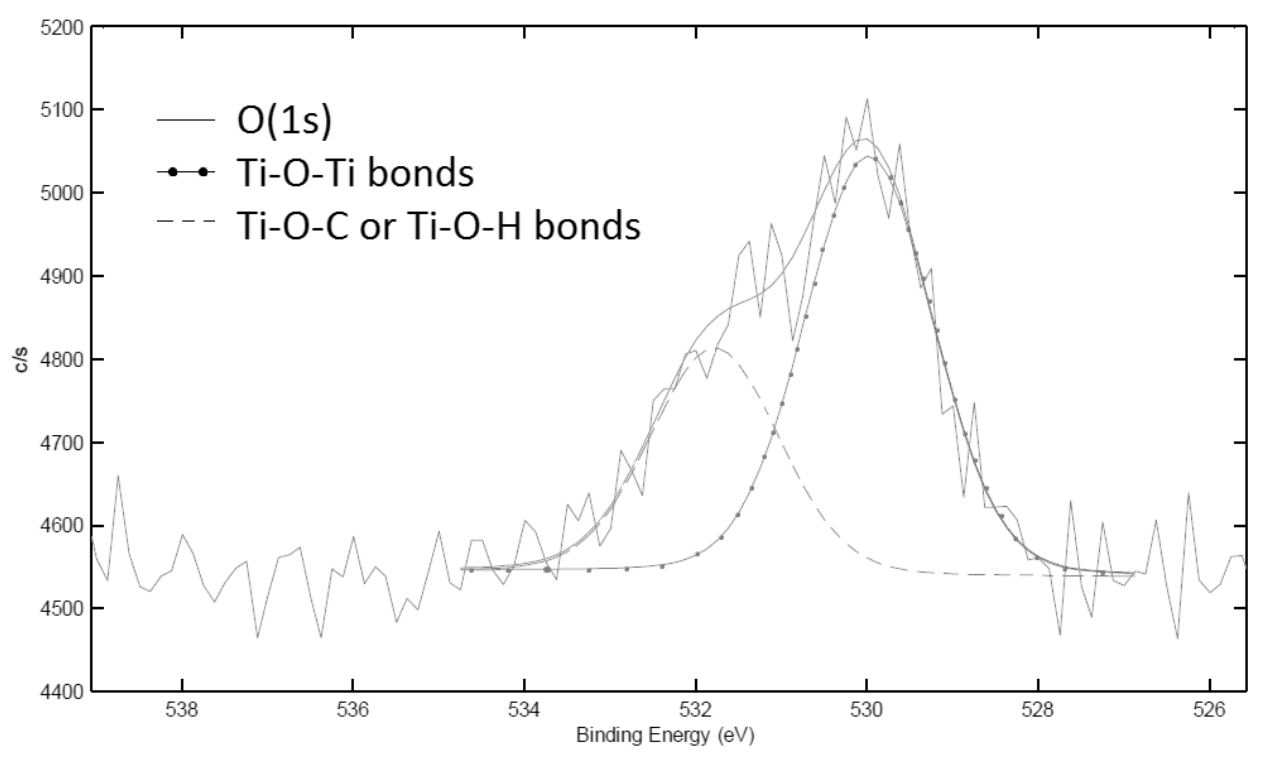

Figure 6 - Deconvolution of the XPS O(1s) peak of the in situ Ti( $\left.\mathrm{O}^{\mathrm{i}} \mathrm{Pr}\right)_{4}-\mathrm{Ac}_{2} \mathrm{O}$ composite

Finally, the $\mathrm{Ti}\left(2 \mathrm{p}_{3 / 2}\right)$ binding energy peak was observed at $458.4 \mathrm{eV}$, corresponding to an oxide form. According to Barlier et al. [28], this value of binding energy corresponded to Ti in an octahedral environment, and therefore to condensed titanium alkoxides. This meant that Ti-O-Ti bond formation resulted in the saturation of the Ti ion coordination sites.

All these data confirmed the in situ creation of $\mathrm{TiO}_{2}$-based inorganic domains with a high condensation degree by the NHSG reaction in molten polypropylene at a high temperature in a few minutes.

In order to determine if the synthesised particles were crystalline or amorphous, samples were analysed by Raman spectroscopy and X-ray diffraction. Raman active modes of anatase and rutile $\mathrm{TiO}_{2}$ were given in Table 4. Compared to neat $\mathrm{PP}$, the Raman spectrum of the $\mathrm{PP} / \mathrm{TiO}_{2}$ reference composite exhibited three additional peaks: a strong peak at $140 \mathrm{~cm}^{-1}$ and two weaker ones at 192 and $635 \mathrm{~cm}^{-1}$ (Figure S3 in SI). Based on the data given in Table 4, the presence of these three bands and their respective intensity allowed for identifying the anatase form.

Table 4 - Raman bands of anatase and rutile $\mathrm{TiO}_{2}[32,33]$ *

\begin{tabular}{cc}
\hline Anatase band $\left(\mathbf{c m}^{-1}\right)$ & Rutile bands $\left(\mathbf{c m}^{-1}\right)$ \\
\hline $144\left(\mathrm{E}_{\mathrm{g}}\right)$ (very strong) & $143\left(\mathrm{~B}_{1 \mathrm{~g}}\right)$ (weak) \\
\hline $197\left(\mathrm{E}_{\mathrm{g}}\right)$ (very weak) & $235\left(\mathrm{~B}_{2 \mathrm{~g}}\right)$ (strong) \\
\hline $400\left(\mathrm{~B}_{1 \mathrm{~g}}\right)$ (very weak) & $447\left(\mathrm{E}_{\mathrm{g}}\right)$ (very strong) \\
\hline $515\left(\mathrm{~B}_{1 \mathrm{~g}}, \mathrm{~A}_{1 \mathrm{~g}}\right)$ (very weak) & $612\left(\mathrm{~A}_{1 \mathrm{~g}}\right)$ (very strong) \\
\hline $640\left(\mathrm{E}_{\mathrm{g}}\right)$ (weak) &
\end{tabular}

${ }^{*} \mathrm{~A}$ and $\mathrm{B}$ for singly degenerate wave functions, $\mathrm{E}$ for doubly degenerate wave functions, $\mathrm{g}$ if the wave function is even

The Raman spectrum of $\mathrm{Ti}\left(\mathrm{O}^{\mathrm{i}} \mathrm{Pr}\right)_{4}-\mathrm{Ac}_{2} \mathrm{O}$ composite (Figure 7) exhibited a broad signal at around $600 \mathrm{~cm}^{-1}$ which was not present on the polypropylene spectrum. This signal was not welldefined and therefore did not correspond to a crystalline phase. Huang et al. [34] showed that amorphous $\mathrm{TiO}_{2}$ exhibits three weak and broad signals at 171,422 and $616 \mathrm{~cm}^{-1}$. The signal that we observed at around $600 \mathrm{~cm}^{-1}$ could therefore be corresponded to amorphous $\mathrm{TiO}_{2}$ domains in the composite. 


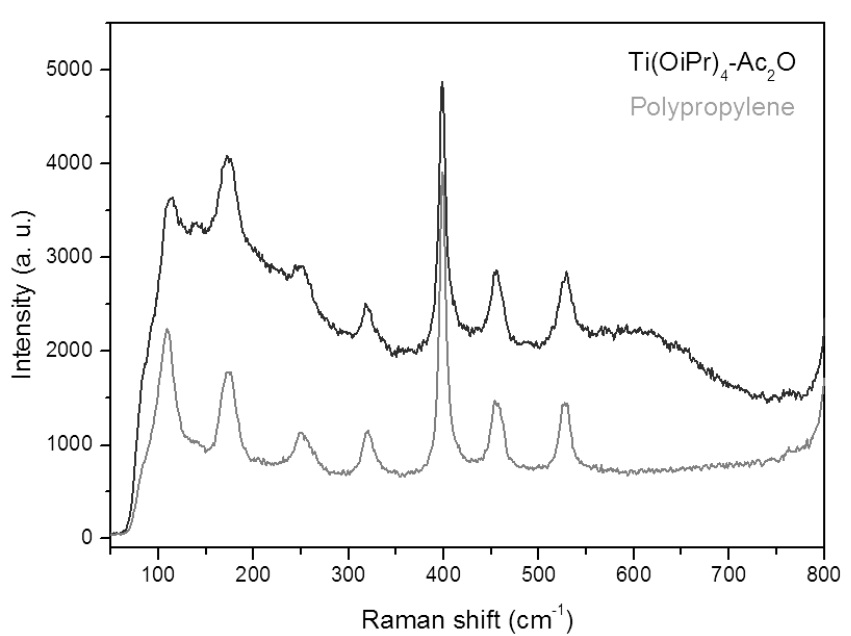

Figure 7 - Raman spectra of the polypropylene and the $\mathrm{Ti}\left(\mathrm{O}^{\mathrm{i}} \mathrm{Pr}\right)_{4}-\mathrm{Ac}_{2} \mathrm{O}$ composite

To complete this analysis, the XRD patterns of $\mathrm{PP} / \mathrm{TiO}_{2}$ reference composite and $\mathrm{Ti}\left(\mathrm{O}^{\mathrm{i}} \mathrm{Pr}\right)_{4}{ }^{-}$ $\mathrm{Ac}_{2} \mathrm{O}$ composite were shown in Figure 8. All observed peaks pointed by vertical lines were associated to the crystalline structures of the polymer matrix. According to Karacan and Benli [35], diffraction peaks at $14.2^{\circ}, 16.9^{\circ}$ and $18.6^{\circ}$ corresponded respectively to (110), (040) and (130) crystal planes of the $\alpha$-monoclinic form of the isotactic polypropylene.

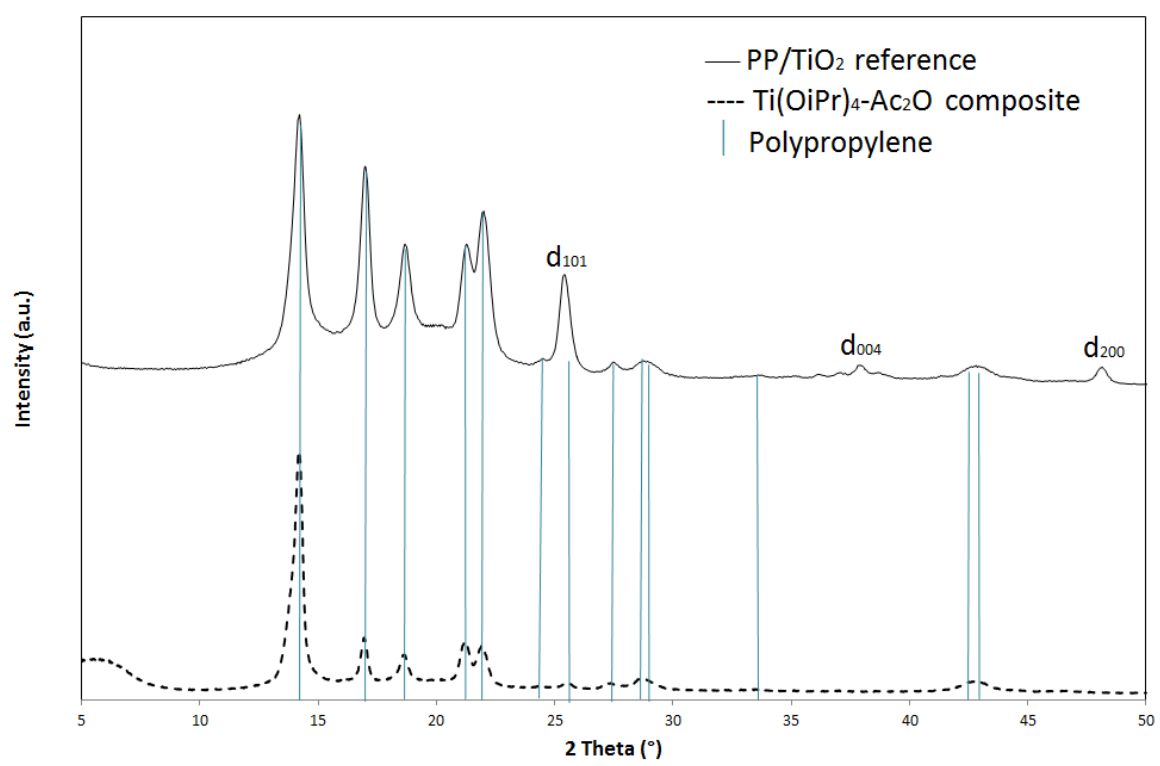

Figure 8 - XRD pattern of $\mathrm{Ti}\left(\mathrm{O}^{\mathrm{i}} \mathrm{Pr}\right)_{4}-\mathrm{Ac}_{2} \mathrm{O}$ composite. Comparison with the pattern obtained for the $\mathrm{PP} / \mathrm{TiO}_{2}$ composite reference

No peaks attributed to the anatase $\left(2 \theta=25.3^{\circ}\right.$ for $\mathrm{d}_{101}, 2 \theta=37.8^{\circ}$ for $\mathrm{d}_{004}$ and $2 \theta=47.9^{\circ}$ for $\left.\mathrm{d}_{200}\right)$ or rutile $\left(2 \theta=27.4^{\circ}\right.$ for $\mathrm{d}_{110}, 2 \theta=35.9^{\circ}$ for $\mathrm{d}_{101}$ and $2 \theta=39.2^{\circ}$ for $\left.\mathrm{d}_{200}\right)$ phases of $\mathrm{TiO}_{2}$ were present in the XRD pattern of the $\mathrm{Ti}\left(\mathrm{O}^{\mathrm{i}} \mathrm{Pr}\right)_{4}-\mathrm{Ac}_{2} \mathrm{O}$ composite [36], whereas in the $\mathrm{PP} / \mathrm{TiO}_{2}$ reference pattern, three peaks associated to anatase structure were present, as expected. None of the typical diffraction peaks associated with $\mathrm{TiO}_{2}$ anatase or rutile forms as previously discussed were observed either by $\mathrm{Hu}$ and Marand [37] in the XRD pattern of a poly(amide-imide)(PAI)/ $\mathrm{TiO}_{2}$ composite. They synthesised the composite by an in situ hydrolytic sol-gel process from tetraethyl titanate in a 
dissolved solution of PAI matrix in $\mathrm{N}, \mathrm{N}$-dimethyl acetamide at room temperature for $36 \mathrm{~h}$. Then the sample was cured at different temperatures (room temperature, 150 and $220^{\circ} \mathrm{C}$ ) for $76 \mathrm{~h}$. Nanosized $\mathrm{TiO}_{2}$ domains were well-dispersed within the PAI matrix thanks to the hydrogen bonding interactions between the amide groups of the PAI and the hydroxyl groups on the inorganic oxide. The authors explained the absence of diffraction $\mathrm{TiO}_{2}$ peaks by the incomplete condensation, given the presence of unreacted alkoxide and hydroxyl groups. In the present case, the observed size of $\mathrm{TiO}_{2}$ domains, the absence of unreacted reactants and the condensation degree were not in line with this explanation. The absence of diffraction peaks of $\mathrm{TiO}_{2}$ was rather explained by the short reaction time and process conditions when the synthesis was carried out by reactive extrusion. However, in the present XRD pattern, the presence of a peak at low value of $2 \theta\left(2 \theta=5.4^{\circ}\right)$ could be observed, not attributed to the polypropylene matrix. Bahloul et al. [26] observed a similar peak in the XRD pattern of $\mathrm{PP} / \mathrm{TiO}_{2}$ nanocomposite synthesised by hydrolytic sol-gel process. Their hypothesis was that this peak was a signature of particle organisation at long distances. Wu [38] also identified an additional peak in the XRD patterns of polycaprolactone $(\mathrm{PCL}) / \mathrm{TiO}_{2}$ and polycaprolactone-graft-acrylic acid (PCLg-AA) $/ \mathrm{TiO}_{2}$ nanocomposites at respectively $2 \theta=2.9^{\circ}$ and $2 \theta=2.6^{\circ}$. He suggested that these low $2 \theta$ values were related to greater spacing between $\mathrm{TiO}_{2}$ nanoparticles and implied better filler/matrix interaction.

To conclude this part, contrary to the anatase $\mathrm{TiO}_{2}$ synthesised in squalane, $\mathrm{TiO}_{2}$-based particles synthesised in molten polypropylene were mostly in amorphous form, as can be observed by XRD and Raman analyses. However, the in situ formation of rather well-condensed $\mathrm{TiO}_{2}$-based particles by NHSG synthesis in molten polypropylene through the ester elimination reaction between $\mathrm{Ti}\left(\mathrm{O}^{\mathrm{i}} \mathrm{Pr}\right)_{4}$ and $\mathrm{Ac}_{2} \mathrm{O}$ was evidenced. In order to further investigate the potential of such a synthesis, we focused in the second part of this study on the role of the nature of reactants on the reaction kinetics and the final dispersion of the in situ formed particles. In that frame, reactants with longer alkyl chains were used and compared to the first system, e.g. the $\mathrm{Ti}\left(\mathrm{O}^{\mathrm{i} P r}\right)_{4}-\mathrm{Ac}_{2} \mathrm{O}$ composite.

\section{Influence of reactants with longer alkyl chains on $\mathrm{TiO}_{2}$ nanoparticle formation and composite morphology}

The analysis of the $\mathrm{Ti}\left(\mathrm{O}^{\mathrm{i}} \mathrm{Pr}\right)_{4}-\mathrm{Ac}_{2} \mathrm{O}$ composite by electron microscopy allowed us to think that weak interfacial interactions took place between the synthesised fillers and the polypropylene matrix in this system. Actually, in Figure 4, some particles were ripped out of the polymer matrix during section preparation by cryo-ultramicrotomy. Thus, in order to enhance the interface between the $\mathrm{TiO}_{2}$ particles and the PP matrix, reactants with longer alkyl chains were chosen with the aim of increasing their affinity with the non-polar reaction medium. Tetrakis 2-ethylhexyl orthotitanate was used as a substituent of titanium isopropoxide and hexanoic anhydride as a substituent of acetic anhydride.

Two aspects were considered for the improvement of $\mathrm{TiO}_{2}$-based particles dispersion by the use of these reactants: the first one was the affinity between the PP matrix and the reactants, and the second one was the compatibility between particles once synthesised and polypropylene. In light of the reaction equations (eq. 4 and eq. 5), the surface of $\mathrm{TiO}_{2}$ particles was surrounded by alkoxy groups coming from the oxygen donor and therefore acid anhydrides should have played a predominant role in the dispersion of the in situ formed particles.

Indications about the affinity between the polypropylene and the different reactants were approached thanks to the solubility parameter $\delta$, which was estimated using Fedors' method [39], even if the temperature and viscosity parameters could not be taken into account in this calculation. 
In the literature, $\delta$ values of polypropylene are between 15.8 and $18.8(\mathrm{MPa})^{1 / 2}[40,41]$, close to the calculated value of $16.0(\mathrm{MPa})^{1 / 2}$. The calculated solubility parameter of each reactant was reported in Table 5. As the solubility parameter $\delta$ values of the titanium dioxide precursors $\mathrm{Ti}\left(\mathrm{O}^{\mathrm{i}} \mathrm{Pr}\right)_{4}$ and $\mathrm{Ti}(2-$ OEtHex $)_{4}$ were very close to each other, i.e. 16.5 and $16.8(\mathrm{MPa})^{1 / 2}$ respectively, and no impact of their solubility in the polypropylene matrix was observed, despite of the difference in alkyl chain length. However, analysing the solubility parameters of oxygen donors, the use of hexanoic anhydride should have favoured the miscibility with polypropylene. Indeed, its solubility parameter $\delta$ of $18.3(\mathrm{MPa})^{1 / 2}$ was closer to the PP solubility parameter than to the solubility parameter $\delta$ of acetic anhydride. So, hexanoic anhydride should have been better dispersed in the polyolefin molten polymer and should have provided a better dispersion of particles thanks to the hexyl groups at the surface of $\mathrm{TiO}_{2}$ particles created in situ.

Table 5 - Solubility parameter of polypropylene and reactants, calculated through Fedors' method[39]

Product
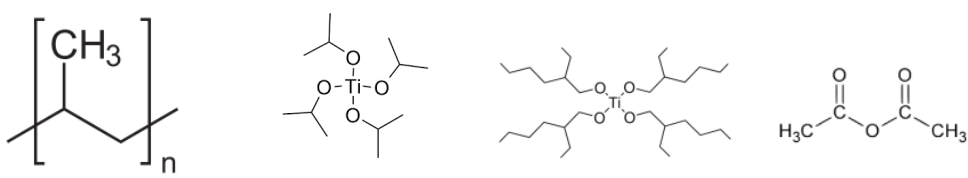

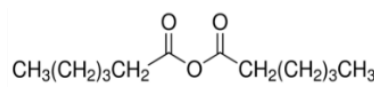

Polypropylene

$\mathrm{Ti}\left(\mathrm{O}^{\mathrm{i}} \mathrm{Pr}\right)_{4}$

$\mathrm{Ti}(2-\mathrm{OEtHex})_{4}$

$\mathrm{Ac}_{2} \mathrm{O}$

$\mathrm{Hex}_{2} \mathrm{O}_{3}$

$\delta(\mathrm{MPa})^{1 / 2}$

16.0

16.5

16.8

19.8

18.3

These different reactants were used for the NHSG synthesis of PP/TiO ${ }_{2}$ composites in order to evaluate their impact on the composite morphology. Reactions were summarised in the experimental part, Table 2. For all the synthesised $\left(\mathrm{Ti}\left(\mathrm{O}^{\mathrm{i}} \mathrm{Pr}\right)_{4}-\mathrm{Hex}_{2} \mathrm{O}_{3}, \mathrm{Ti}(\mathrm{OEtHex})_{4}-\mathrm{Ac}_{2} \mathrm{O}\right.$ and $\left.\mathrm{Ti}(\mathrm{OEtHex})_{4}-\mathrm{Hex}_{2} \mathrm{O}_{3}\right)$ composites, but not for the $\mathrm{Ti}\left(\mathrm{O}^{\prime} \mathrm{Pr}\right)_{4}-\mathrm{Ac}_{2} \mathrm{O}$ composite, some of the by-products could have been extracted by vacuum pumping. These by-products were characterised by GC-MS coupling analysis (Figure $\mathrm{S} 4$ in $\mathrm{SI}$ ). In all three cases, the expected by-product was detected. For the $\mathrm{Ti}(\mathrm{OEtHex})_{4}-\mathrm{Ac}_{2} \mathrm{O}, \mathrm{Ti}\left(\mathrm{O}^{\prime} \mathrm{Pr}\right)_{4}-\mathrm{Hex}_{2} \mathrm{O}_{3}$ and $\mathrm{Ti}(\mathrm{OEtHex})_{4}-\mathrm{Hex}_{2} \mathrm{O}_{3}$ composites, corresponding esters (2ethylhexyl acetate, isopropyl hexanoate and 2-ethylhexyl hexanoate) had elution times of 5.5, 4.5 and 7.7 minutes, respectively. The presence of alcohol detected in different composites (2ethylhexanol with an elution time between 4 and 5 minutes for the $\mathrm{Ti}(\mathrm{OEtHex})_{4}-\mathrm{Ac}_{2} \mathrm{O}$ and $\mathrm{Ti}(\mathrm{OEtHex})_{4}-\mathrm{Hex}_{2} \mathrm{O}_{3}$ composites; propan-2-ol with an elution time at 1.9 minutes for the $\mathrm{Ti}\left(\mathrm{O}^{\mathrm{i}} \mathrm{Pr}\right)_{4^{-}}$ $\mathrm{Hex}_{2} \mathrm{O}_{3}$ composite) could have suggested a contribution from hydrolytic reactions, but a low proportion of the corresponding alcohol was already present in the commercial precursors. It was noteworthy that no acid anhydride was detected, confirming that the acetoxylation step was complete before the extraction zone. For the $\mathrm{Ti}\left(\mathrm{O}^{\prime} \mathrm{Pr}\right)_{4}-\mathrm{Hex}_{2} \mathrm{O}_{3}$ and $\mathrm{Ti}(\mathrm{OEtHex})_{4}-\mathrm{Ac}_{2} \mathrm{O}$ samples, the boiling points of the esters were lower than the extrusion temperature and a part of them had evaporated at the die exit, which hindered a complete quantitative evaluation of the by-product. On the contrary, for the last sample $\left(\mathrm{Ti}(\mathrm{OEtHex})_{4}-\mathrm{Hex}_{2} \mathrm{O}_{3}\right)$, the ester by-product presented a higher boiling point than the reactive extrusion temperature and remained in the composite and may have modified the nature of the matrix (no purer polypropylene) and thus the expected compatibilisation based on the calculation of solubility parameters.

From the Soxhlet extraction, the remaining by-product in the Ti(OEtHex $)_{4}-\mathrm{Ac}_{2} \mathrm{O}, \mathrm{Ti}\left(\mathrm{O}^{\mathrm{i}} \mathrm{Pr}\right)_{4}$ $\mathrm{Hex}_{2} \mathrm{O}_{3}$ and $\mathrm{Ti}(\mathrm{OEtHex})_{4}-\mathrm{Hex}_{2} \mathrm{O}_{3}$ composites corresponded to $3.11 \mathrm{wt} \%, 2.15 \mathrm{wt} \%$ and $17.0 \mathrm{wt} \%$, 
respectively, of the initial composite mass. For Ti(OEtHex $)_{4}-\mathrm{Ac}_{2} \mathrm{O}$ and $\mathrm{Ti}\left(\mathrm{O}^{\mathrm{i}} \mathrm{Pr}\right)_{4}-\mathrm{Hex}_{2} \mathrm{O}_{3}$, as described previously, a part of by-products had evaporated during the extrusion process. However, for the last composite $\mathrm{Ti}(\mathrm{OEtHex})_{4}-\mathrm{Hex}_{2} \mathrm{O}_{3}$, the mass balance of the reaction could be established from the quantity of by-products extracted by vacuum pumping and by Soxhlet extraction. Experimentally, 35 $w t \%$ of by-products were extracted from the composite, very close to the theoretical value of $36 \mathrm{wt} \%$ expected for a total condensation reaction. The ${ }^{1} \mathrm{H}$ NMR spectrum of the extracted medium (Figure S5 in SI) showed the presence of the expected ester by the chemical shifts at 2.2 and 3.9 ppm and 2ethyl-1-hexanol by the chemical shift at $3.5 \mathrm{ppm}$ (corresponding to a contribution of $7 \%$ of the hydrolytic reaction of the titanium precursor). A conversion rate close to $93 \%$ was determined from this method. However, it should be noted that condensation reactions may continue throughout the Soxhlet extraction at $110^{\circ} \mathrm{C}$, although shorter extraction times (24 or $48 \mathrm{~h}$ ) led to the same condensation degree. It was noteworthy that there was no signal for hexanoic anhydride, again demonstrating that the first step of the reaction, e.g. acetoxylation, was complete.

Extruded composites were characterised by SEM and TEM to compare the particle dispersion states (Figure 9). By taking as a reference the $\mathrm{Ti}\left(\mathrm{O}^{\mathrm{i}} \mathrm{Pr}\right)_{4}-\mathrm{Ac}_{2} \mathrm{O}$ composite morphology previously analysed, the use of $\mathrm{Ti}(2-\mathrm{OEtHex})_{4}$ with acetic anhydride ( $\left.\mathrm{Ti}(\mathrm{OEtHex})_{4}-\mathrm{Ac}_{2} \mathrm{O}\right)$ did not lead to smaller particles or aggregates, but a finer particle dispersion was observed. This result agreed with the determination of solubility parameters of the two different titanium dioxide precursors. In the TEM micrograph of the $\mathrm{Ti}\left(\mathrm{O}^{\prime} \mathrm{Pr}\right)_{4}-\mathrm{Ac}_{2} \mathrm{O}$ sample, some holes were observed at the interface between the polymer matrix and agglomerates. However, particles of the $\mathrm{Ti}(\mathrm{OEtHex})_{4}-\mathrm{Ac}_{2} \mathrm{O}$ composite were not ripped from the PP matrix during sample preparation, which evidenced a better interface with polypropylene. Besides, SEM and TEM images of the sample Ti(O'Pr $)_{4}-\mathrm{Hex}_{2} \mathrm{O}_{3}$ displayed the finest particle dispersion, revealing as predicted previously a better dispersion of the reactant in the PP matrix and a better dispersion of the in situ created $\mathrm{TiO}_{2}$ particles, due to the presence of hexyl chains at the surface of particles.

Based on these assessments, good dispersion and small particle diameter may have been expected for the sample $\mathrm{Ti}(\mathrm{OEtHex})_{4}-\mathrm{Hex}_{2} \mathrm{O}_{3}$, given the long alkyl chains of reactants. Nevertheless, from SEM observations, it was found that particle/aggregate diameters were the largest of the four samples. A possible explanation for such a result was the high quantity of the remaining by-products that may have formed non-miscible domains (where $\mathrm{TiO}_{2}$-based particles could preferentially grow). Thus, the presence of these separated phases within the polymer matrix could have favoured the agglomeration of the created $\mathrm{TiO}_{2}$ particles through higher affinities towards this phase in comparison to the PP matrix. It was noteworthy that, in the transmission electron micrograph of the sample after by-product extraction, it was observed, in addition to the previously discussed micrometric $\mathrm{TiO}_{2}$ domains, nanoparticles with a diameter less than $10 \mathrm{~nm}$ (micrograph at bottom right in Figure 9). These nanoparticles formed a network that was visible only after by-product extraction and only in the $\mathrm{Ti}(\mathrm{OEtHex})_{4}-\mathrm{Hex}_{2} \mathrm{O}_{3}$ sample, showing the effect of alkyl chain length on the in situ formation of $\mathrm{TiO}_{2}$-based particles. 

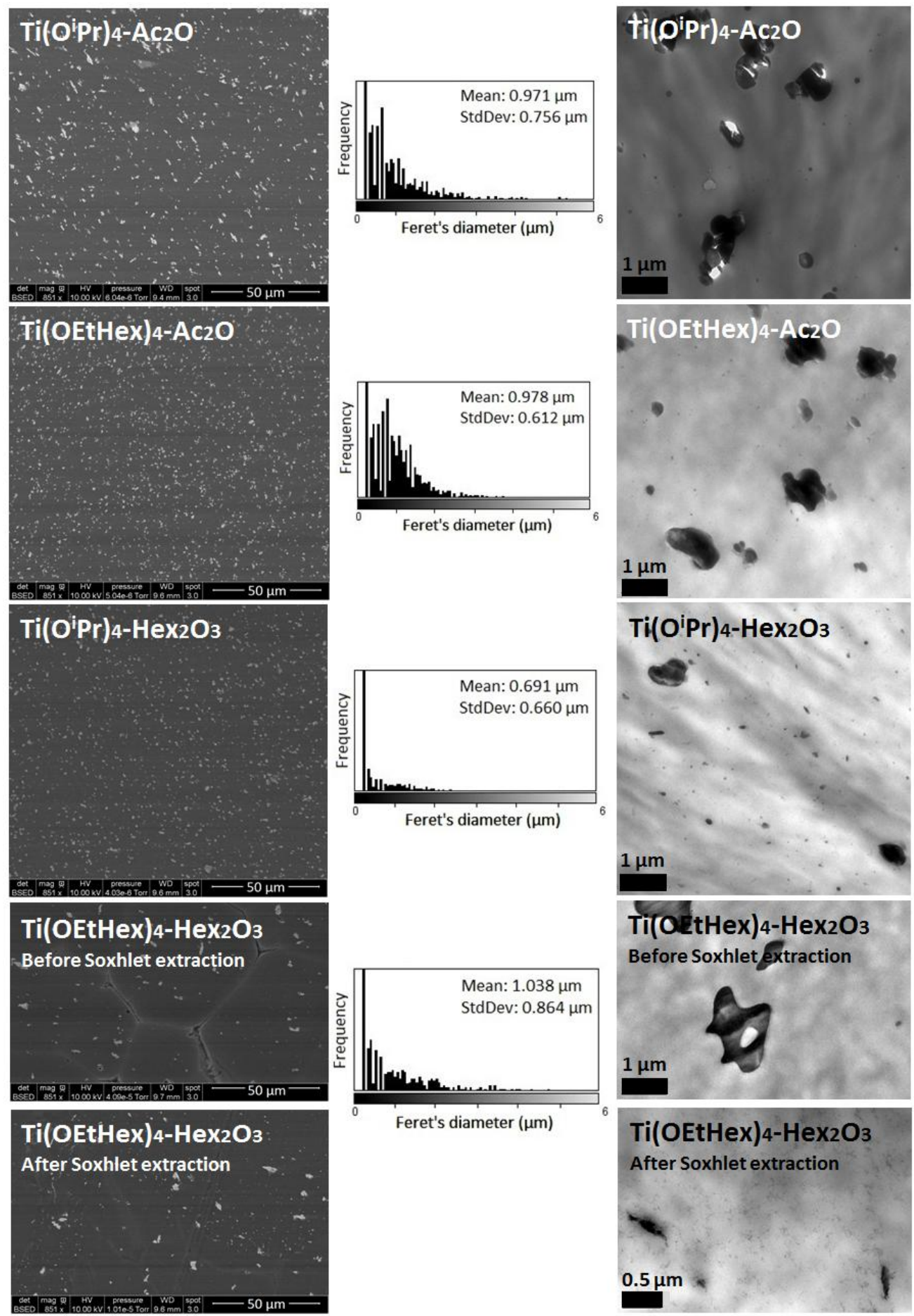

Feret's diameter $(\mu \mathrm{m})$

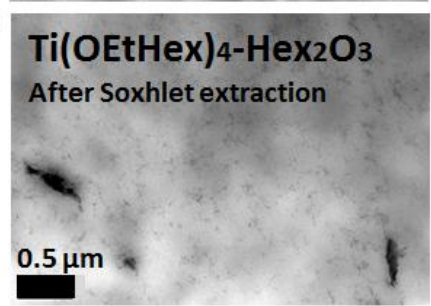

Figure 9 -SEM images, diameter distribution of particles/aggregates calculated from SEM images and TEM images of $\mathrm{PP} / \mathrm{TiO}_{2}$ composites synthesized by reactive extrusion

XRD analyses carried out on these samples showed the absence of anatase and rutile peaks, as for the $\mathrm{Ti}\left(\mathrm{O}^{\mathrm{i} P r}\right)_{4}-\mathrm{Ac}_{2} \mathrm{O}$ sample. The peak observed at $5.4^{\circ}$ in the XRD pattern of $\mathrm{Ti}\left(\mathrm{O}^{\mathrm{i}} \mathrm{Pr}\right)_{4}-\mathrm{Ac}_{2} \mathrm{O}$ seemed to be shifted towards small angles for the new studied samples (Figure 10). Indeed, for $\mathrm{Ti}(\mathrm{OEtHex})_{4}-\mathrm{Ac}_{2} \mathrm{O}$ composite, the signal was centred at around $4.3^{\circ}$ and for both $\mathrm{Ti}\left(\mathrm{O}^{\mathrm{i}} \mathrm{Pr}\right)_{4}-\mathrm{Hex}_{2} \mathrm{O}_{3}$ and $\mathrm{Ti}(\mathrm{OEtHex})_{4}-\mathrm{Hex}_{2} \mathrm{O}_{3}$ composites, the signal was centred at $3.9^{\circ}$. As discussed before, this 
corresponded to an improvement in $\mathrm{TiO}_{2}$-based particle dispersion, as seen by Wu et al. [38]. Moreover, the peak intensity was greatest for the $\mathrm{Ti}\left(\mathrm{O}^{\mathrm{i}} \mathrm{Pr}\right)_{4}-\mathrm{Hex}_{2} \mathrm{O}_{3}$ composite, which may have been correlated with a homogeneous distribution of $\mathrm{TiO}_{2}$-based particles in the PP matrix.

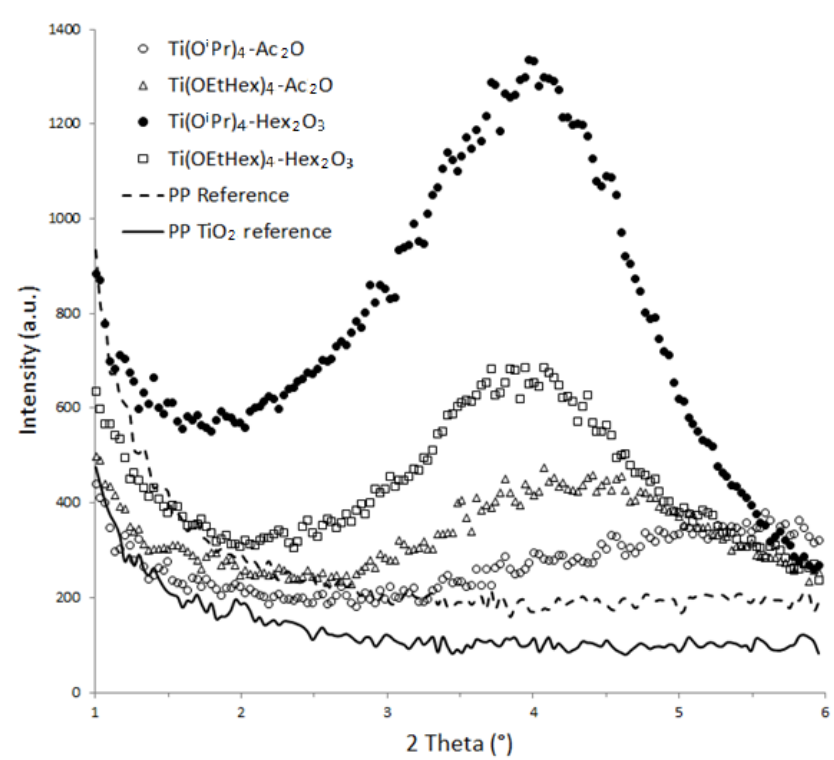

Figure 10 - XRD patterns diffractograms at low angle of polypropylene, $\mathrm{PP} / \mathrm{TiO}_{2}$ reference composite and $\mathrm{PP} / \mathrm{TiO}_{2}$ composites synthesized by reactive extrusion by NHSG reaction

Finally, the viscoelastic behaviour of $\mathrm{PP} / \mathrm{TiO}_{2}$ composites in the melt state was investigated to provide complementary information on filler/matrix interactions. According to the Einstein law (eq. 6) that predicted the impact of the addition of particles on the viscoelastic behaviour of a material, the introduction of $5 \mathrm{wt} \%$ of microparticles should not affect the viscoelastic behaviour of the PP matrix (Figure 11).

$$
G^{*}(\omega)=G_{m}^{*}(\omega)\left(\frac{1+\frac{3}{2} \varphi_{r}}{1-\varphi_{r}}\right)
$$

where $G^{*}$ and $G^{*}{ }_{m}$ were respectively the complex shear modulus of the composite and of the PP matrix, and $\varphi_{r}$ was the volume fraction of $\mathrm{TiO}_{2}$ particles, $\varphi_{r}=0.012$ in this case.

Nevertheless, the in situ synthesis of nanoparticles did not lead necessarily to the same viscoelastic behaviour, as demonstrated by Bahloul et al. [42] For a $\mathrm{TiO}_{2}$ particle concentration of $6 \mathrm{wt} \%$; the authors observed the appearance of a plateau at low frequencies, corresponding to a solid-like behaviour, common for nanocomposite materials. Two mechanisms explained this phenomenon: filler/filler or polymer matrix/filler interactions [43]. 


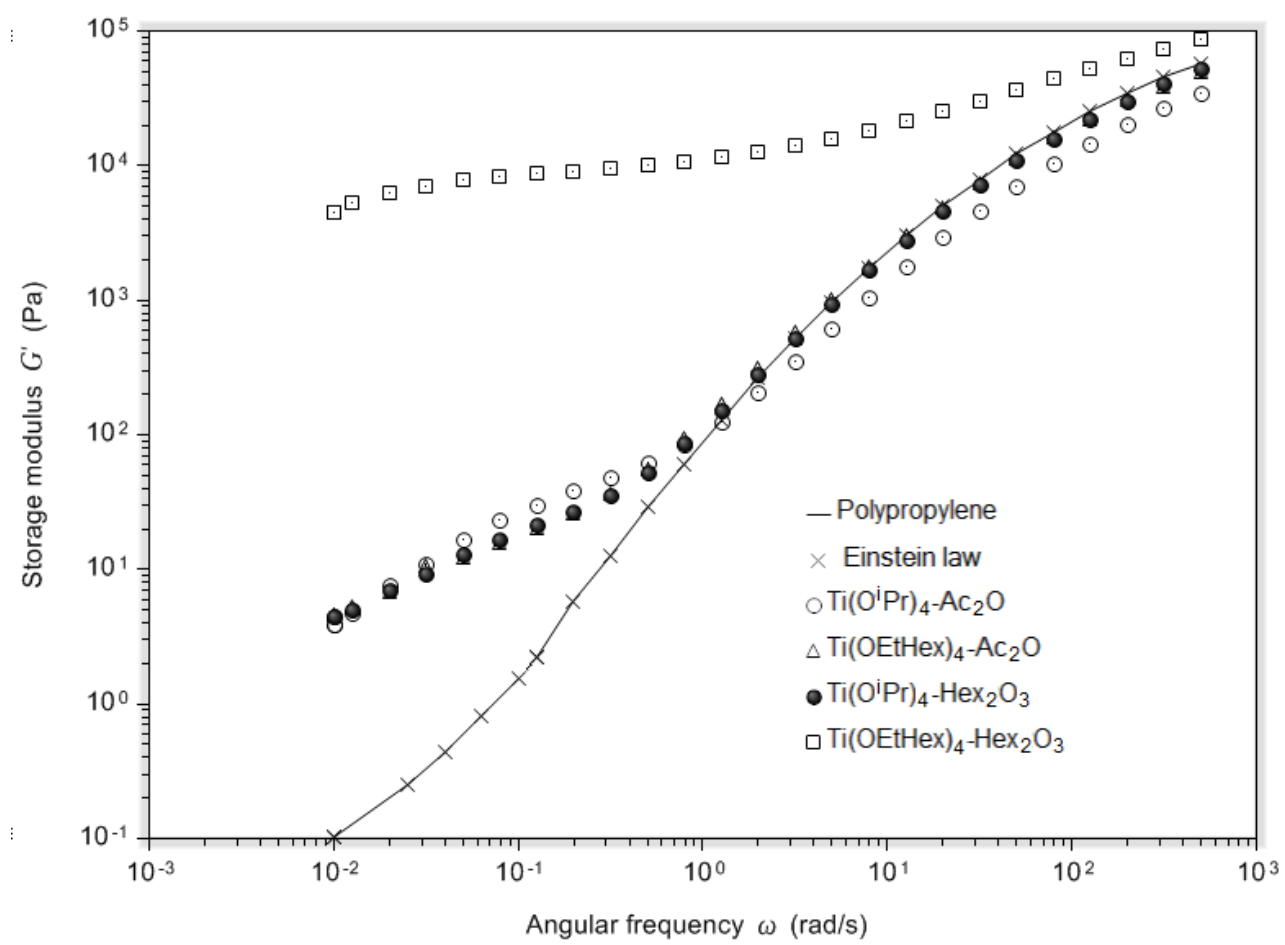

Figure 11 - Viscoelastic behavior of $\mathrm{PP} / \mathrm{TiO}_{2}$ composites after by-products extraction synthesized from NHSG reactions in extruder. Variation of the storage modulus versus frequencies measured under nitrogen atmosphere at $200{ }^{\circ} \mathrm{C}$

In Figure 11, a modification of the viscoelastic behaviour of in situ $\mathrm{PP} / \mathrm{TiO}_{2}$ composites compared with the polypropylene matrix was observed. More precisely, the storage modulus $\mathrm{G}^{\prime}$ increased at low frequencies, modifying the terminal zone of relaxation. There was no permanent plateau at low frequencies, as generally observed for nanocomposites, but a second relaxation mechanism. The same modification of the storage modulus was reported by Acierno et al. [45] who elaborated $\mathrm{PP} / \mathrm{TiO}_{2}$ nanocomposites by introducing $\mathrm{TiO}_{2}$ nanoparticles in the molten polypropylene. The authors related this behaviour to the existence of inorganic nanoparticle clusters, which formed a dynamic population with different kinetics of relaxation to the host polymer. Lacoste et al. [46] also observed a shoulder for $G^{\prime}$ at low frequencies when they functionalised PET with new chain extenders. The PET branched structure led to the storage modulus increase. However, in our case, the results of size exclusion chromatography analyses in Table 6 showed that the average molar masses between neat polypropylene and composites remained unchanged. Consequently, the observed modification of viscoelastic behaviour was due to the presence of fillers, as explained by Acierno et al. [45]. It was noteworthy that the increase in the storage modulus was greatest for the composite $\mathrm{Ti}(\mathrm{OEtHex})_{4}-\mathrm{Hex}_{2} \mathrm{O}_{3}$. The network formed by the very small particles observed in this composite after Soxhlet extraction explained this storage modulus difference due to an increase in particle-particle interactions and the formation of particle aggregates at the nanoscale with a particle size below $10 \mathrm{~nm}$. Indeed, the other composites did not exhibit such small particles.

Table 6 - Size exclusion chromatography results for PP reference and $\mathrm{PP} / \mathrm{TiO}_{2}$ composites

\begin{tabular}{lccc}
\hline & $\mathrm{Mn}\left(\mathrm{g} \mathrm{mol}^{-1}\right)$ & $\mathrm{Mw}\left(\mathrm{g} \mathrm{mol}^{-1}\right)$ & $\mathrm{Mw} / \mathrm{Mn}$ \\
\hline PP reference & 85800 & 183000 & 2,13 \\
\hline $\mathrm{Ti}\left(\mathrm{O}^{\mathrm{i}} \mathrm{Pr}\right)_{4}-\mathrm{A}_{2} \mathrm{O}$ & 84600 & 181000 & 2,14 \\
\hline $\mathrm{Ti}(\mathrm{OEtHex})_{4}-\mathrm{Hex}_{2} \mathrm{O}_{3}$ & 88300 & 183000 & 2,07 \\
\hline
\end{tabular}




\section{Conclusions}

$\mathrm{PP} / \mathrm{TiO}_{2}$ composites were originally synthesised by combining a non-hydrolytic sol-gel process and reactive extrusion. First, syntheses in an alkane medium allowed for determining the reactivity between acetic anhydride and titanium isopropoxide at $240^{\circ} \mathrm{C}$ for $1 \mathrm{~h}$, then $\mathrm{TiO}_{2}$ based particles were prepared in situ from this non-hydrolytic reaction in a molten polypropylene matrix. The reaction in model medium led to the formation of anatase particles. Nanorods (about $10 \mathrm{~nm}$ ) were assembled to form spherical secondary particles of a few micrometres. In PP medium, XPS analysis evidenced the formation of $\mathrm{TiO}_{2}$-based particles by the presence of $\mathrm{Ti}-\mathrm{O}$ - $\mathrm{Ti}$ bonds and allowed for determining a condensation degree of $79 \%$. The mean size of $\mathrm{TiO}_{2}$ particles synthesised in situ in polypropylene was $1 \mu \mathrm{m}$. Particles synthesised in situ in molten polypropylene were mostly amorphous, according to Raman and XRD spectroscopy.

To improve the $\mathrm{TiO}_{2}$-based particle dispersion, reactants with longer alkyl chains were used. The finest particle dispersion was obtained with the use of hexanoic anhydride instead of acetic anhydride, with a mean particle size of about $700 \mathrm{~nm}$. This enhancement was partially attributable to hexyl groups remaining at the surface of $\mathrm{TiO}_{2}$-based particles. Rheology measurements showed a modification of the viscoelastic behaviour at low frequencies, indicating the presence of aggregates and filler/matrix interactions. This modification of the storage modulus was greatest for the composite $\mathrm{Ti}(\mathrm{OEtHex})_{4}-\mathrm{Hex}_{2} \mathrm{O}_{3}$, due to the presence of a network of very small particles in the polypropylene matrix.

\section{Declaration of competing interest}

The authors declare that they have no known competing financial interests or personal relationships that could have appeared to influence the work reported in this paper.

\section{Acknowledgment}

This work was financed by the Agence Nationale pour la Recherche (project ANR-16-CE080015 SYNCOPE). The authors would like to thank Pierre Alcouffe and all the staff of the Technological Center of Microstructures of the University of Lyon 1 for their help and the Science et Surface laboratory for XPS measurements.

\section{References}

[1] J. Yang, J.-J. Zhao, C.-R. Han, J.-F. Duan, Keys to enhancing mechanical properties of silica nanoparticle composites hydrogels: The role of network structure and interfacial interactions, $\begin{array}{llllll}\text { Composites Science } & \end{array}$ https://doi.org/10.1016/j.compscitech.2014.02.003.

[2] A. Laachachi, M. Cochez, E. Leroy, P. Gaudon, M. Ferriol, J.M.L. Cuesta, Effect of $\mathrm{Al}_{2} \mathrm{O}_{3}$ and $\mathrm{TiO}_{2}$ nanoparticles and APP on thermal stability and flame retardance of PMMA, Polym. Adv. Technol. 17 (2006) 327-334. https://doi.org/10.1002/pat.690.

[3] J.D. Mangadlao, H. Xu, E. Baer, R.C. Advincula, In Situ Photogeneration of Palladium Nanoparticles in Thermoplastic Polyurethane: Photopatterning and Enhanced Oxygen Barrier Property, Macromolecular Chemistry and Physics. $218 \quad$ (2017) 1700289. https://doi.org/10.1002/macp.201700289. 
[4] E. Fages, J. Pascual, O. Gimeno, D. Garcia-Sanoguera, R. Balart, Study of Antibacterial Properties of Polypropylene Filled With Surfactant-Coated Silver Nanoparticles, Polymer Engineering \& Science. 51 (2011) 804-811. https://doi.org/10.1002/pen.21889.

[5] M. lijima, M. Kobayakawa, M. Yamazaki, Y. Ohta, H. Kamiya, Anionic Surfactant with Hydrophobic and Hydrophilic Chains for Nanoparticle Dispersion and Shape Memory Polymer Nanocomposites, J. Am. Chem. Soc. 131 (2009) 16342-16343. https://doi.org/10.1021/ja906655r.

[6] K. Radad, M. Al-Shraim, R. Moldzio, W.-D. Rausch, Recent advances in benefits and hazards of engineered nanoparticles, Environmental Toxicology and Pharmacology. 34 (2012) 661-672. https://doi.org/10.1016/j.etap.2012.07.011.

[7] V. Bounor-Legaré, P. Cassagnau, In situ synthesis of organic-inorganic hybrids or nanocomposites from sol-gel chemistry in molten polymers, Progress in Polymer Science. 39 (2014) 1473-1497. https://doi.org/10.1016/j.progpolymsci.2014.04.003.

[8] K. Kaneko, N. Yadav, K. Takeuchi, B. Maira, M. Terano, T. Taniike, Versatile strategy for fabrication of polypropylene nanocomposites with inorganic network structures based on catalyzed in-situ sol-gel reaction during melt mixing, Composites Science and Technology. 102 (2014) 120-125. https://doi.org/10.1016/j.compscitech.2014.07.024.

[9] W. Bahloul, V. Bounor-Legaré, G. Seytre, P. Cassagnau, Influence of a non-polar medium (alkane and molten polypropylene) on the titanium n-butoxide hydrolysis-condensation reactions, Journal of Sol-Gel Science and Technology. 57 (2011) 86-94. https://doi.org/10.1007/s10971010-2327-1.

[10] W. Bahloul, Génération in situ de dioxyde de titane par réactions d'hydrolyse-condensations dans une matrice polymère fondu, thesis, Lyon 1, 2010. http://www.theses.fr/2010LYO10124 (accessed June 25, 2019).

[11] Aqueous and Nonaqueous Sol-Gel Chemistry, in: Metal Oxide Nanoparticles in Organic Solvents, Springer London, London, 2009: pp. 7-18. http://link.springer.com/10.1007/978-184882-671-7_2 (accessed January 24, 2017).

[12] P.H. Mutin, A. Vioux, Recent advances in the synthesis of inorganic materials via non-hydrolytic condensation and related low-temperature routes, Journal of Materials Chemistry A. 1 (2013) 11504. https://doi.org/10.1039/c3ta12058a.

[13] A. Vioux, Nonhydrolytic Sol-Gel Routes to Oxides, Chem. Mater. 9 (1997) 2292-2299. https://doi.org/10.1021/cm970322a.

[14] M. Niederberger, G. Garnweitner, Organic Reaction Pathways in the Nonaqueous Synthesis of Metal Oxide Nanoparticles, Chem. Eur. J. 12 (2006) 7282-7302. https://doi.org/10.1002/chem.200600313.

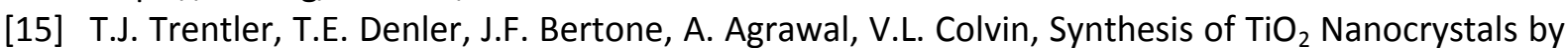
Nonhydrolytic Solution-Based Reactions, Journal of the American Chemical Society. 121 (1999) 1613-1614. https://doi.org/10.1021/ja983361b.

[16] M. Niederberger, M.H. Bard, G.D. Stucky, Benzyl alcohol and transition metal chlorides as a versatile reaction system for the nonaqueous and low-temperature synthesis of crystalline nano-objects with controlled dimensionality, J. Am. Chem. Soc. 124 (2002) 13642-13643. https://doi.org/10.1021/ja027115i.

[17] Y. Wang, S. Kim, N. Louvain, J.G. Alauzun, P.H. Mutin, Acetic Anhydride as an Oxygen Donor in the Non-Hydrolytic Sol-Gel Synthesis of Mesoporous $\mathrm{TiO}_{2}$ with High Electrochemical Lithium Storage Performances, Chemistry - A European Journal. 25 (2019) 4767-4774. https://doi.org/10.1002/chem.201806073.

[18] D. Morselli, M. Messori, F. Bondioli, Poly(methyl methacrylate)- $\mathrm{TiO}_{2}$ nanocomposite obtained by non-hydrolytic sol-gel synthesis, Journal of Materials Science. 46 (2011) 6609-6617. https://doi.org/10.1007/s10853-011-5610-9.

[19] N. Godbert, T. Mastropietro, T. Poerio, Mesoporous $\mathrm{TiO}_{2}$ Thin Films: State of the Art, in: 2018. https://doi.org/10.5772/intechopen.74244. 
[20] J.P. Mofokeng, A.S. Luyt, T. Tábi, J. Kovács, Comparison of injection moulded, natural fibrereinforced composites with PP and PLA as matrices, Journal of Thermoplastic Composite Materials. 25 (2012) 927-948. https://doi.org/10.1177/0892705711423291.

[21] C. Longo, M. Savaris, M. Zeni, R.N. Brandalise, A.M.C. Grisa, Degradation study of polypropylene (PP) and bioriented polypropylene (BOPP) in the environment, Materials Research. 14 (2011) 442-448. https://doi.org/10.1590/S1516-14392011005000080.

[22] M. Day, J.D. Cooney, M. MacKinnon, Degradation of contaminated plastics: a kinetic study, Polymer Degradation and Stability. 48 (1995) 341-349. https://doi.org/10.1016/01413910(95)00088-4.

[23] S. Esthappan, S. Kumbamala Kuttappan, R. Joseph, Thermal and mechanical properties of polypropylene/titanium dioxide nanocomposite fibers, Materials \& Design. 37 (2012) 537-542. https://doi.org/10.1016/j.matdes.2012.01.038.

[24] D. Aydemir, G. Uzun, H. Gumus, S. Yıldız, S. Gumus, T. BARDAK, G. Gündüz, Nanocomposites of polypropylene/nano titanium dioxide: Effect of loading rates of $\mathrm{Nano}^{-\mathrm{TiO}_{2}}$, Materials Science. 22 (2016) 364-369. https://doi.org/10.5755/j01.ms.22.3.8217.

[25] J.M. Lannon, Q. Meng, Analysis of a Poly(propylene)(PP) Homopolymer by XPS, Surface Science Spectra. 6 (1999) 79-82. https://doi.org/10.1116/1.1247902.

[26] W. Bahloul, F. Mélis, V. Bounor-Legaré, P. Cassagnau, Structural characterization and antibacterial activity of $\mathrm{PP} / \mathrm{TiO}_{2}$ nanocomposites prepared by an in situ sol-gel method, Materials Chemistry and Physics. 134 (2012) 399-406. https://doi.org/10.1016/j.matchemphys.2012.03.008.

[27] Z. Hamden, S. Bouattour, A.M. Ferraria, D.P. Ferreira, L.F. Vieira Ferreira, A.M. Botelho do Rego, S. Boufi, In situ generation of $\mathrm{TiO}_{2}$ nanoparticles using chitosan as a template and their photocatalytic activity, Journal of Photochemistry and Photobiology A: Chemistry. 321 (2016) 211-222. https://doi.org/10.1016/j.jphotochem.2016.02.008.

[28] V. Barlier, V. Bounor-Legaré, G. Boiteux, J. Davenas, D. Léonard, Hydrolysis-condensation reactions of titanium alkoxides in thin films: A study of the steric hindrance effect by X-ray photoelectron spectroscopy, Applied Surface Science. 254 (2008) 5408-5412. https://doi.org/10.1016/j.apsusc.2008.02.076.

[29] L. Ge, M. Xu, H. Fang, M. Sun, Preparation of $\mathrm{TiO}_{2}$ thin films from autoclaved sol containing needle-like anatase crystals, Applied Surface Science. 253 (2006) 720-725. https://doi.org/10.1016/j.apsusc.2005.12.162.

[30] Y. Gao, Y. Masuda, K. Koumoto, Light-Excited Superhydrophilicity of Amorphous $\mathrm{TiO}_{2}$ Thin Films Deposited in an Aqueous Peroxotitanate Solution, Langmuir. 20 (2004) 3188-3194. https://doi.org/10.1021/la0303207.

[31] T. Shaikh, A. Rathore, H. Kaur, Poly (Lactic Acid) Grafting of $\mathrm{TiO}_{2}$ Nanoparticles : A Shift in Dye Degradation Performance of $\mathrm{TiO}_{2}$ from UV to Solar Light, ChemistrySelect. 2 (2017) 6901-6908. https://doi.org/10.1002/slct.201701560.

[32] E. Haroponiatowski, R. Rodrigueztalavera, M. Delacruzheredia, O. Canocorona, R. Arroyomurillo, Crystallization of Nanosized Titania Particles Prepared by the Sol-Gel Process, J. Mater. Res. 9 (1994) 2102-2108. https://doi.org/10.1557/JMR.1994.2102.

[33] J. Parker, R. Siegel, Raman Microprobe Study of Nanophase $\mathrm{TiO}_{2}$ and Oxidation-Induced Spectral Changes, J. Mater. Res. 5 (1990) 1246-1252. https://doi.org/10.1557/JMR.1990.1246.

[34] P.J. Huang, H. Chang, C.T. Yeh, C.W. Tsai, Phase transformation of $\mathrm{TiO}_{2}$ monitored by ThermoRaman spectroscopy with TGA/DTA, Thermochim. Acta. 297 (1997) 85-92. https://doi.org/10.1016/S0040-6031(97)00168-8.

[35] I. Karacan, H. Benli, An X-ray Diffraction study for isotactic polypropylene fibers produced with take-up speeds of 2500-4250 m/min, Tekstil ve Konfeksiyon. 21 (2011) 201-209.

[36] K. Sakurai, M. Mizusawa, X-ray Diffraction Imaging of Anatase and Rutile, Anal. Chem. 82 (2010) 3519-3522. https://doi.org/10.1021/ac9024126. 
[37] Q. Hu, E. Marand, In situ formation of nanosized $\mathrm{TiO}_{2}$ domains within poly(amide-imide) by a sol-gel process, Polymer. 40 (1999) 4833-4843. https://doi.org/10.1016/S00323861(98)00264-X.

[38] C.-S. Wu, In situ polymerization of titanium isopropoxide in polycaprolactone: Properties and characterization of the hybrid nanocomposites, Journal of Applied Polymer Science. 92 (2004) 1749-1757. https://doi.org/10.1002/app.20135.

[39] R.F. Fedors, A method for estimating both the solubility parameters and molar volumes of liquids, Polymer Engineering \& Science. $14 \quad$ (1974) 147-154. https://doi.org/10.1002/pen.760140211.

[40] A.S. Michaels, W.R. Vieth, H.H. Alcalay, The solubility parameter of polypropylene, Journal of Applied Polymer Science. 12 (1968) 1621-1624. https://doi.org/10.1002/app.1968.070120711.

[41] C. Onuoha, O. Onyemaobi, C. Anyakwo, G. Onuegbu, Morphology and Physical/End-Use Properties of Recycled Polypropylene-Corn Cob Powder Composites, International Journal of $\begin{array}{lllll}\text { Engineering } & \text { and } & \text { Technologies. }\end{array}$ https://doi.org/10.18052/www.scipress.com/IJET.11.1.

[42] W. Bahloul, V. Bounor-Legaré, L. David, P. Cassagnau, Morphology and viscoelasticity of PP/TiO nanocomposites prepared by in situ sol-gel method, Journal of Polymer Science Part B: Polymer Physics. 48 (2010) 1213-1222. https://doi.org/10.1002/polb.22012.

[43] P. Cassagnau, Melt rheology of organoclay and fumed silica nanocomposites, Polymer. 49 (2008) 2183-2196. https://doi.org/10.1016/j.polymer.2007.12.035.

[44] Q. Zhang, L.A. Archer, Poly(ethylene oxide)/Silica Nanocomposites: Structure and Rheology, Langmuir. 18 (2002) 10435-10442. https://doi.org/10.1021/la026338j.

[45] D. Acierno, G. Filippone, G. Romeo, P. Russo, Rheological aspects of $\mathrm{PP}-\mathrm{TiO}_{2}$ micro and nanocomposites: A preliminary investigation, Macromol. Symp. 247 (2007) 59-66. https://doi.org/10.1002/masy.200750108.

[46] J.-F. Lacoste, V. Bounor-Legaré, M.-F. Llauro, C. Monnet, P. Cassagnau, A. Michel, Functionalization of poly(ethylene terephthalate) in the melt state: Chemical and rheological aspects, Journal of Polymer Science Part A: Polymer Chemistry. 43 (2005) 2207-2223. https://doi.org/10.1002/pola.20696. 
2

3

4

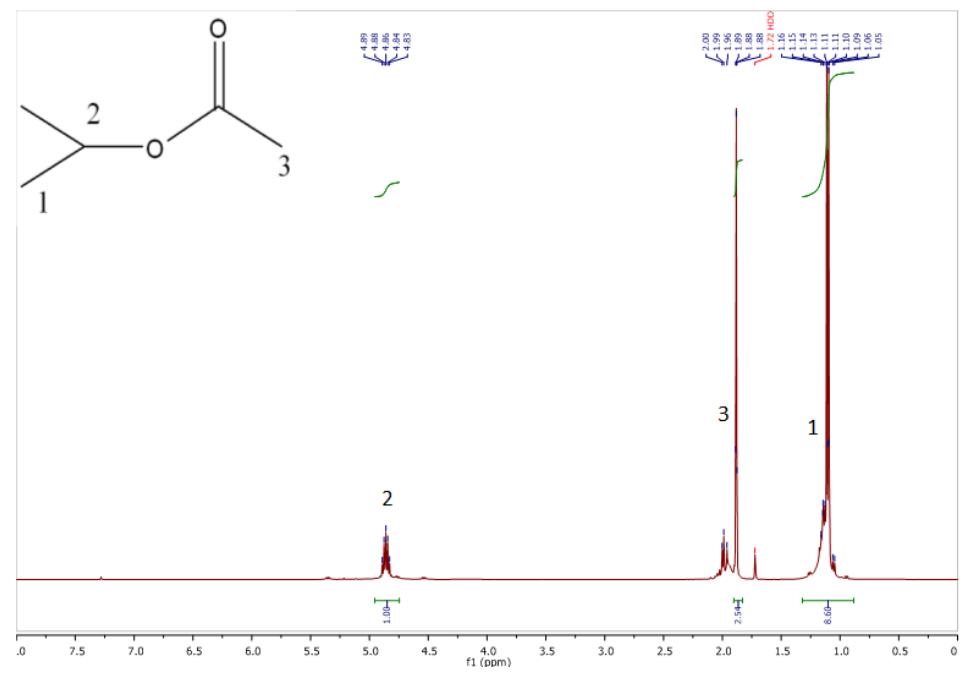

Figure $\mathbf{S 1}-{ }^{1} \mathrm{H}$ NMR spectrum in $\mathrm{CDCl}_{3}$ of the reaction medium obtained from mixing stoichiometric quantities of $\mathrm{Ti}\left(\mathrm{O}^{\mathrm{i}} \mathrm{Pr}\right)_{4}$ and $\mathrm{Ac}_{2} \mathrm{O}$ for 10 minutes at room temperature

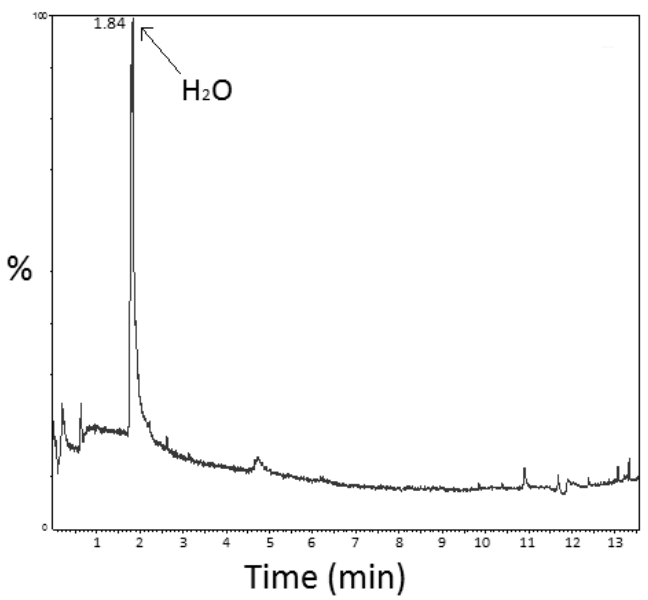

Figure S2 - Chromatogram of $\mathrm{Ti}\left(\mathrm{O}^{\mathrm{i}} \mathrm{Pr}\right)_{4}-\mathrm{Ac}_{2} \mathrm{O}$ composite obtained by TDA-GC-MS coupling at $200{ }^{\circ} \mathrm{C}$ under helium atmosphere 


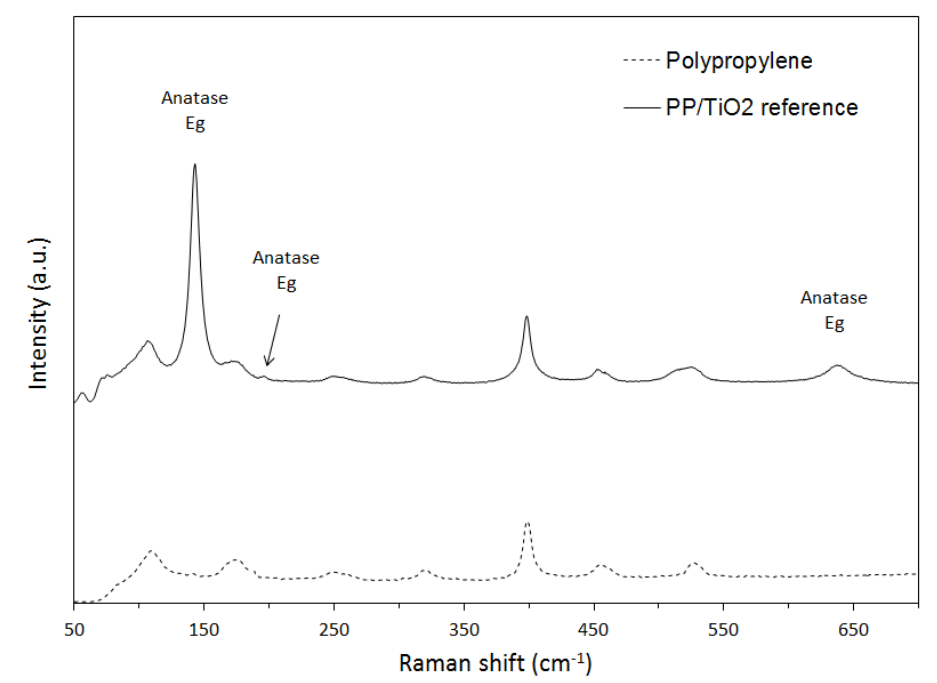

1

2

3

4

5

6

7

8

9

Figure S3 - Raman spectra of the polypropylene and the $\mathrm{PP} / \mathrm{TiO}_{2}$ reference composite

$\mathrm{Ti}(\mathrm{OEtHex})_{4-\mathrm{Ac} 2} \mathrm{O}$

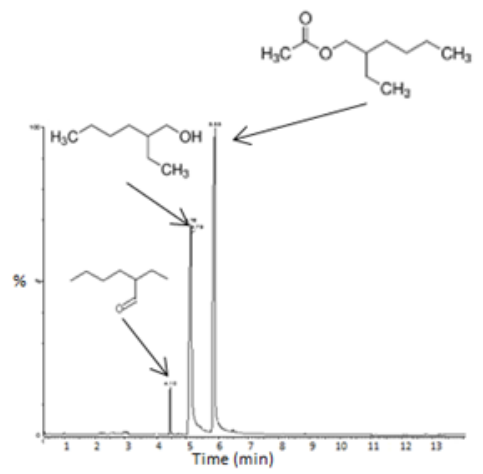

$\mathrm{Ti}(\mathrm{OiPr})_{4}-\mathrm{Hex}_{2} \mathrm{O}_{3}$

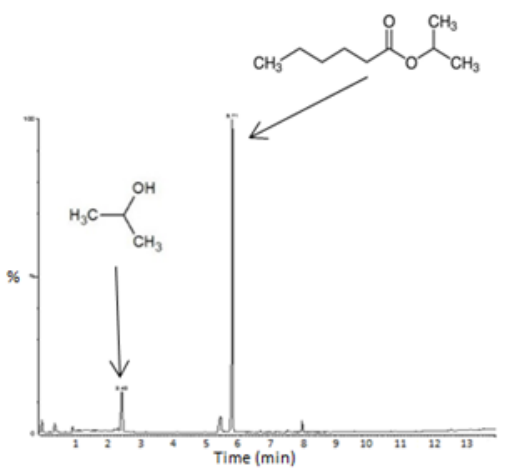

Ti(OEtHex) $)_{4}-\mathrm{Hex}_{2} \mathrm{O}_{3}$

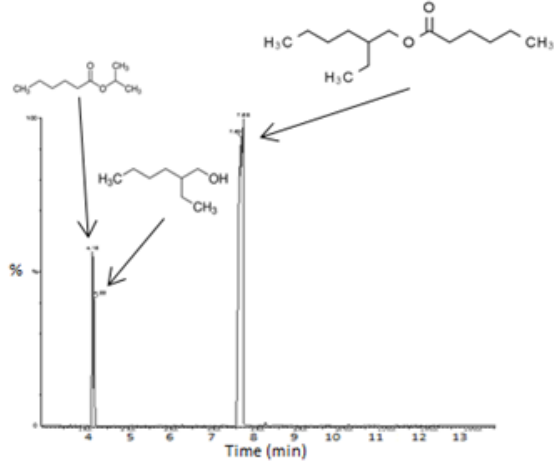

Figure S4 - Chromatograms of by-products extracted by vacuum pumping and peaks assignment by mass spectroscopy from the $\mathrm{Ti}\left(\mathrm{O}^{\mathrm{i}} \mathrm{Pr}\right)_{4}-\mathrm{Hex}_{2} \mathrm{O}_{3} ; \mathrm{Ti}(\mathrm{OEtHex})_{4}-\mathrm{Ac}_{2} \mathrm{O} ; \mathrm{Ti}(\mathrm{OEtHex})_{4}-\mathrm{Hex}_{2} \mathrm{O}_{3}$ composites synthesis

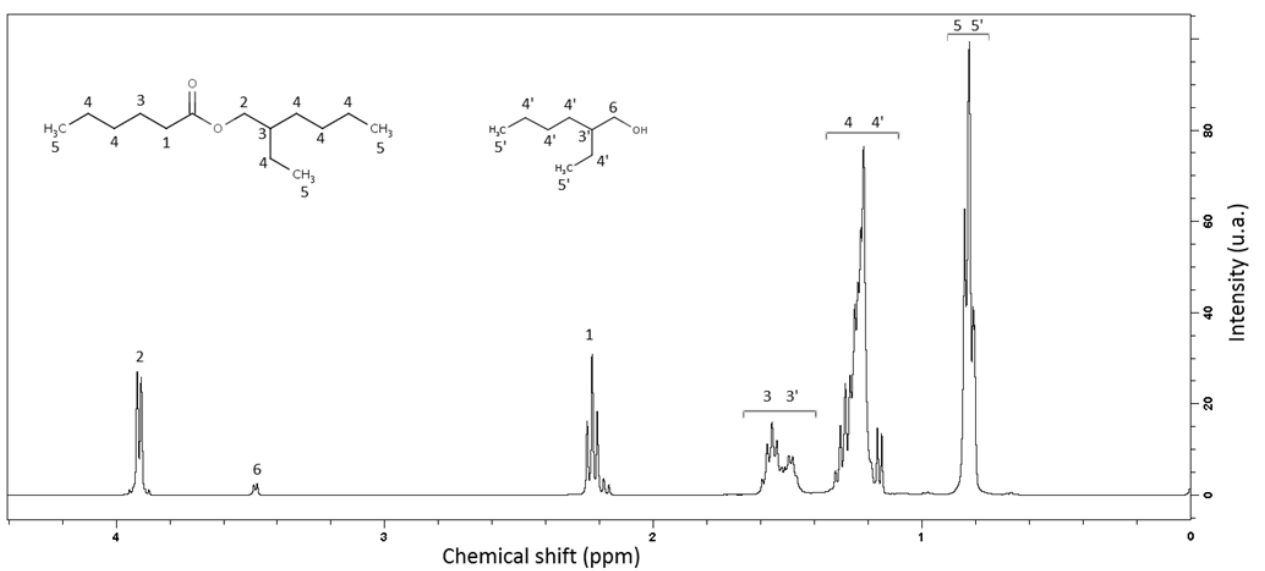

Figure $\mathrm{S} 5-{ }^{1} \mathrm{H}$ NMR spectrum in $\mathrm{CDCl}_{3}$ of the extracted by-products of $\mathrm{Ti}(\mathrm{OEtHex})_{4}-\mathrm{Hex}_{2} \mathrm{O}_{3}$ composite 